\title{
Evolution of Phase Constitution, Morphology and Corrosion Behavior of ZnCo Coating Containing Graphene Oxide
}

\author{
SWEETY ARORA and CHANDAN SRIVASTAVA
}

The morphology, phase constitution and corrosion behavior of a pristine $\mathrm{ZnCo}$ coating (obtained from an acidic bath) and $\mathrm{ZnCo}$ composite coatings containing different amounts of graphene oxide were studied. To achieve this, electrochemical impedance spectroscopy, potentiodynamic polarization studies, scanning electron microscopy, X-ray diffraction, atomic force microscopy, contact angle measurement and weight loss measurements were conducted. It was observed that the morphology, phase constitution and corrosion resistance of the coatings were highly sensitive to the amount of graphene oxide contained in the coatings. For lower graphene oxide amounts, a compact and smooth morphology was observed, whereas higher graphene oxide content produced a non-uniform morphology with cracks on the coating surface essentially due to the deposition of agglomerated graphene oxide in the coating matrix. All the coatings contained a mixture of $\mathrm{Zn}$ phase and $\mathrm{Zn}_{10.63} \mathrm{Co}_{2.34}$ intermetallic phase. The volume fraction of the nobler intermetallic phase increased with an increase in the graphene oxide amount. The corrosion rate of the coatings decreased with the initial addition of graphene oxide to reach a minimum after which it increased with continued addition of graphene oxide. The initial reduction in the corrosion rate was attributed to the enhancement in the coating compactness and smoothness with the addition of graphene oxide, impermeability of the graphene oxide and enhancement of the relative volume fraction of the intermetallic phase. The enhancement of the corrosion rate after the optimum, which gave the lowest corrosion rate, was due to the increase in the morphologic roughness, cracks and surface defects in the coatings primarily due to non-uniform deposition of agglomerated graphene oxide in the coating matrix. Surface defects did not allow the formation of a continuous passive protection layer.

https://doi.org/10.1007/s11661-020-05812-2

(c) The Minerals, Metals \& Materials Society and ASM International 2020

\section{INTRODUCTION}

$\mathrm{ZN}_{\mathrm{N}}$ coatings are widely used to protect steel from degradation due to corrosion. ${ }^{[1,2]}$ The mechanism of corrosion protection is sacrificial in nature. The preferential oxidation of $\mathrm{Zn}$ leads to the formation of hydroxide-oxide film (white rust), which acts as an effective insulator. ${ }^{[3]}$ Recent reports have established that alloying of zinc with other metals, such as $\mathrm{Ni}, \mathrm{Fe}$, $\mathrm{Co}$ and $\mathrm{Mn}$, leads to improved corrosion resistance behavior of zinc. ${ }^{[4]}$ Furthermore, properties such as the hardness, ductility and weldability of zinc are also improved because of alloying. Boshkov et al. ${ }^{[8]}$ studied the corrosion of zinc alloys with cobalt (electrically more positive than zinc) and Mn (less negative than zinc).

SWEETY ARORA and CHANDAN SRIVASTAVA are with the Department of Materials Engineering, Indian Institute of Science, Bangalore 560012, India. Contact e-mail: csrivastava@iisc.ac.in Manuscript submitted February 8, 2020.
They found that in both cases the coatings were more corrosion resistant than the pristine $\mathrm{Zn}$ coating owing to the formation of the same corrosion product, i.e., zinc hydroxide chloride hydrate (ZHC).

$\mathrm{Zn}-\mathrm{Co}$ alloys exhibit significantly higher corrosion resistance than pristine $\mathrm{Zn} .^{[9-11]}$ Ramanauskas et al. ${ }^{[12]}$ established that a decrease in the lattice parameter in the $\mathrm{Zn}-\mathrm{Co}$ alloy is responsible for its enhanced corrosion resistance compared with only Zn. Pedro De Lima-Neto et al. ${ }^{[13]}$ studied the corrosion behavior of only $\mathrm{Zn}$ and $\mathrm{Zn}$-Co electrodeposits. Their results revealed a higher corrosion tendency for high cobalt content coatings because of the selective dissolution of $\mathrm{Zn}$-rich phases leading to the formation of cracks. Sohi and Gharahcheshmeh $^{[14,15]}$ established that the corrosion resistance behavior of $\mathrm{ZnCo}$ coatings is influenced by their texture. They reported that among the single-phase ZnCo coatings, those with smaller grain sizes exhibited higher corrosion resistance than those with coarser grain sizes. The higher grain boundary density accelerates the formation of a stable passive film. 
It has been shown that incorporation of foreign particles into the matrix might lead to significant enhancement of the corrosion resistance behavior of the matrix phase. ${ }^{[16-21]}$ This has also been illustrated in the case of $\mathrm{Zn}-\mathrm{Co}$ coatings. Tulio et al. ${ }^{[22]}$ studied the effect of the addition of micron-sized $\mathrm{SiC}$ and $\mathrm{Al}_{2} \mathrm{O}_{3}$ particles on $\mathrm{ZnCo}$ electrodeposition and reported that the presence of $\mathrm{SiC}$ particles increases the reduction rate of both $\mathrm{Zn}$ and Co ions. The effect was more prevalent in case of cobalt ions, which leads to an increased cobalt content in the matrix resulting in enhanced corrosion resistance behavior. Co-deposition of $\mathrm{Al}_{2} \mathrm{O}_{3}$ particles in the $\mathrm{ZnCo}$ matrix has a negative effect on cobalt deposition specially for high cobalt content in the electrolyte. The probable reason for this phenomenon was enhanced adsorption of cobalt/zinc ion on $\mathrm{Al}_{2} \mathrm{O}_{3}$ particles. Boshkov et al. ${ }^{[23]}$ investigated the effect of addition of organic polymer particles (polyethers) on the corrosion behavior of chromated $\mathrm{ZnCo}$ coatings. They observed that the inclusion of organic particles triggers the formation of additional micro-cracks during the chromating process. This leads to localized destruction of the metal film, thereby increasing its dissolution and corrosion.

Several recent studies have shown that addition of carbonaceous materials, such as graphene, graphene oxide and carbon nanotubes, leads to enhancement of the corrosion resistance behavior of the matrix material. $^{[24-27]}$ The observed enhancement of the corrosion resistance has been attributed to the impermeability to the passage of the corrosive media for graphene and graphene oxide and hydrophobicity for $\mathrm{CNTs}^{[28,29]}$ and also to the microstructural alterations of the matrix phase observed in all cases. These microstructural alterations include changes in grain sizes, changes in the growth pattern/texture (surface orientation), compositional segregations at heterophase interfaces and evolution of the micro-texture with respect to the relative change in the fraction of low- and high-angle grain boundaries. ${ }^{[30,31]}$ Between graphene and graphene oxide, incorporation of graphene oxide is preferred ${ }^{[32]}$ as the presence of oxygen-containing functional groups makes it hydrophilic in nature. This hydrophilicity facilitates easier dispersion in water-based electrolytes, which are typically used for producing the protective coatings.

In the present study, the effect of the graphene oxide concentration on the evolution of the coating morphology, phase constitution and corrosion behavior of ZnCo-graphene oxide coatings has been investigated. It is shown that an optimum amount of graphene oxide in the coating significantly enhances the corrosion resistance of the composite coatings.

\section{EXPERIMENT}

\section{A. Graphene Oxide Synthesis}

Graphene oxide synthesis was done using the modified Hummer's method. ${ }^{[33]}$ The synthesis method has been described in one of our earlier papers. ${ }^{[31]}$

\section{B. Electrodeposition}

Coatings of $\mathrm{ZnCo}$ and $\mathrm{ZnCo}$ containing different amounts of graphene oxide (GO) were obtained using a methacrylate bath having an inter-electrode distance of $4 \mathrm{~cm}$. Platinum foil was used as anode, and a mild steel plate with an exposed area of $2 \mathrm{~cm} \times 2 \mathrm{~cm}$ was used as cathode. The steel substrate was mechanically polished using emery papers of 80, 400, 1000, 1500 and 2500 grades and then pickled in a 50 pct diluted $\mathrm{HCl}$ solution (by volume) for 5 seconds before electrodeposition. Sodium sulfate and CTAB (cetyl trimethyl ammonium bromide) were used as additives to obtain better morphology. Optimized bath compositions and deposition parameters used for producing the $\mathrm{ZnCo-GO}$ composite coatings are provided in Table I.

\section{Coating Characterization}

The surface morphology and composition of electrodeposits were determined by a FEI ESEM quanta 200 scanning electron microscope (SEM) and energy-dispersive X-ray spectroscopy (EDS), respectively. X-ray diffraction (XRD) profiles were recorded to determine the presence of intermetallic in the coating matrix, using a PANalytical JDX-8030 diffractometer operating at $40 \mathrm{kV}$ and using $\mathrm{Cu} \mathrm{K}$ alpha radiation. A FEI TITAN transmission electron microscope (TEM) operating at $300 \mathrm{KeV}$ was used to obtain bright-field images of the sample cross section prepared using SEM-FIB (focused ion beam). A Bruker Tensor 2 instrument was used to obtain the FTIR profile of as-synthesized graphene oxide powder. An atomic force microscope (JPK nanoWizardR 3 AFM) instrument was used to determine the surface roughness of the deposits. The analysis was carried out using Nanosurf Easy Scan 2 software. An OCA 15EC optical contact angle measuring and contour analysis system was used to calculate the contact angle of water droplets over the coating surface.

Electrochemical properties of the electrodeposited $\mathrm{ZnCo}$ and $\mathrm{ZnCo}-\mathrm{GO}$ coatings were determined at room temperature in aerated 3.5 wt pet $\mathrm{NaCl}$ solution (pH 6.5) using a CHI 604E electrochemical workstation, and the corrosion rate was determined using extrapolation of the potentiodynamic polarization curves. For this, a three-electrode setup with a platinum foil as counter electrode and saturated $\mathrm{Ag} / \mathrm{AgCl}$ as reference electrode was used to measure the current of the working electrode. The samples were stabilized until a constant value of the open circuit potential was obtained. The samples were polarized to $\pm 200 \mathrm{mV}$ at a scan rate of $1 \mathrm{mV} / \mathrm{s}$ for these measurements. Electrochemical impedance studies were performed in the frequency range $100 \mathrm{kHz}$ to $0.01 \mathrm{~Hz}$ with $5 \mathrm{mV}$ as sinusoidal signal amplitude. Corrosion resistance of the deposits were also measured after 24 and 48 hours of exposure in $3.5 \mathrm{wt}$ pct sodium chloride solution at room temperature $\left(25 \pm 5^{\circ} \mathrm{C}\right)$. All the measurements were performed at least thrice to ensure the reproducibility of results. 
Table I. Electrolyte Bath Composition and Deposition Parameters Used for Electrodeposition of ZnCo and ZnCo-GO Composite Coatings

\begin{tabular}{|c|c|c|}
\hline Sample Name & \multicolumn{2}{|c|}{ Bath Composition and Operating Parameters } \\
\hline $\mathrm{ZnCo}$ & $\begin{array}{l}\mathrm{ZnSO}_{4} \cdot 7 \mathrm{H}_{2} \mathrm{O}(150 \mathrm{~g} / \mathrm{L}) \\
\mathrm{CoSO}_{4} \cdot 7 \mathrm{H}_{2} \mathrm{O}(150 \mathrm{~g} / \mathrm{L}) \\
\mathrm{Na}_{2} \mathrm{SO}_{4}(75 \mathrm{~g} / \mathrm{L}) \\
\text { CTAB }(0.04 \mathrm{~g} / \mathrm{L})\end{array}$ & $\begin{array}{l}\quad \mathrm{pH}: 2.3 \\
\text { time: } 20 \mathrm{~min} \\
\text { stirring RPM: } 200 \\
\text { temperature: } 25 \pm 3{ }^{\circ} \mathrm{C} \\
\text { current density: } 0.100 \mathrm{~A} / \mathrm{cm}^{2}\end{array}$ \\
\hline $\mathrm{ZnCo}$ GO1 & $\mathrm{ZnCo}+\mathrm{GO}(0.1 \mathrm{~g} / \mathrm{L})$ & \\
\hline $\mathrm{ZnCo} \mathrm{GO} 2$ & $\mathrm{ZnCo}+\mathrm{GO}(0.2 \mathrm{~g} / \mathrm{L})$ & \\
\hline $\mathrm{ZnCo} \mathrm{GO} 3$ & $\mathrm{ZnCo}+\mathrm{GO}(0.4 \mathrm{~g} / \mathrm{L})$ & \\
\hline $\mathrm{ZnCo} \mathrm{GO} 4$ & $\mathrm{ZnCo}+\mathrm{GO}(0.6 \mathrm{~g} / \mathrm{L})$ & \\
\hline $\mathrm{ZnCo} \mathrm{GO} 5$ & $\mathrm{ZnCo}+\mathrm{GO}(0.8 \mathrm{~g} / \mathrm{L})$ & \\
\hline $\mathrm{ZnCo} \mathrm{GO6}$ & $\mathrm{ZnCo}+\mathrm{GO}(1 \mathrm{~g} / \mathrm{L})$ & \\
\hline
\end{tabular}
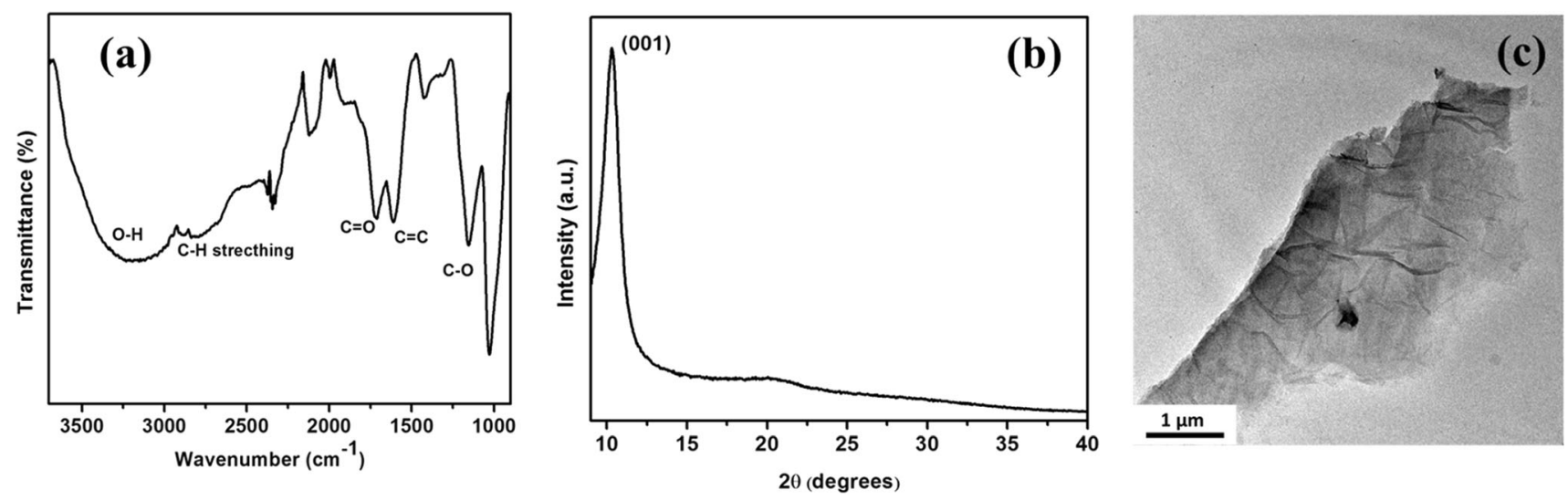

Fig. 1-(a) FT-IR, (b) XRD and (c) TEM of as-synthesized GO sheets.

\section{RESULTS}

\section{A. Graphene Oxide (GO) Characterization}

The presence of different oxygen functionalities was confirmed using FT-IR spectroscopy (Figure 1(a)). The broad peak around $\sim 3200 \mathrm{~cm}^{-1}$ represents stretching vibration of the $\mathrm{O}-\mathrm{H}$ group. The peak at $\sim 1616 \mathrm{~cm}^{-1}$ depicts $\mathrm{sp}^{2}$ hybridized $\mathrm{C}=\mathrm{C}$ bonds and at $\sim 1715 \mathrm{~cm}^{-1}$ corresponds to $\mathrm{C}=\mathrm{O}$ moieties in the $\mathrm{GO}$ lattice. The $\sim 965$ and $1045 \mathrm{~cm}^{-1}$ peaks correspond to the epoxy and $\mathrm{C}-\mathrm{O}$ group, respectively. The FT-IR spectra indicate the oxidation of the graphitic lattice to graphene oxide. Figure 1(b) shows the XRD profile obtained from the as-synthesized GO. The diffraction peak corresponding to the (001) plane of GO can be observed at $2 \theta=10.3 \mathrm{deg}$ revealing the typical inter-layer spacing of $0.85 \mathrm{~nm}$ in the as-synthesized stacked GO layers. The above results confirmed the formation of graphene oxide. The sheet morphology of graphene oxide was confirmed from TEM images. A representative brightfield TEM image is provided in Figure 1(c).

\section{B. Coating Characterization}

The electrodeposition of the Zn-Co alloy showed an anomalous behavior. ${ }^{[34]}$ Table I shows that to deposit a
$\mathrm{ZnCo}$ alloy an electrolytic bath containing $\mathrm{Zn}$ and $\mathrm{Co}$ ions in equi-molar ratio was used. Bahrololoom et al. ${ }^{[34]}$ tried to explain this behavior while using a sulfate bath. They noticed that $\mathrm{Co}^{+2}$ hydrates to form the $[\mathrm{Co}$ $\left.\left(\mathrm{H}_{2} \mathrm{O}\right)_{6}\right]^{+2}$ complex, which reduces to cobalt later, thereby decreasing the cobalt reduction rate. Several other authors ${ }^{[9-11]}$ have reported cobalt reduction as two consecutive one-electron-step reactions given as:

$$
\begin{gathered}
\mathrm{Co}^{+2}+\mathrm{OH}^{-}+\mathrm{e}^{-} \rightarrow \mathrm{CoOH}_{\mathrm{ads}}, \\
\mathrm{CoOH}_{\mathrm{ads}}+\mathrm{H}^{+}+\mathrm{e}^{-} \rightarrow \mathrm{Co}+\mathrm{H}_{2} \mathrm{O} .
\end{gathered}
$$

Representative low- $(1500 \times)$ and high-magnification $(2500 \times)$ micrographs of the coating morphology of $\mathrm{ZnCo}$ and $\mathrm{ZnCo-GO}$ composites are presented in Figures 2 and 3, respectively. The coating morphology of the pristine $\mathrm{ZnCo}$ coating was non-uniform and turned granular and relatively more compact with the initial graphene oxide addition. For higher graphene oxide additions, non-uniform morphology and cracks are observed. This was possibly due to the non-uniform distribution of agglomerated graphene oxide in the coating matrix (as described later). Among the coatings, the $\mathrm{ZnCo-GO} 3$ coating exhibited the smoothest and 


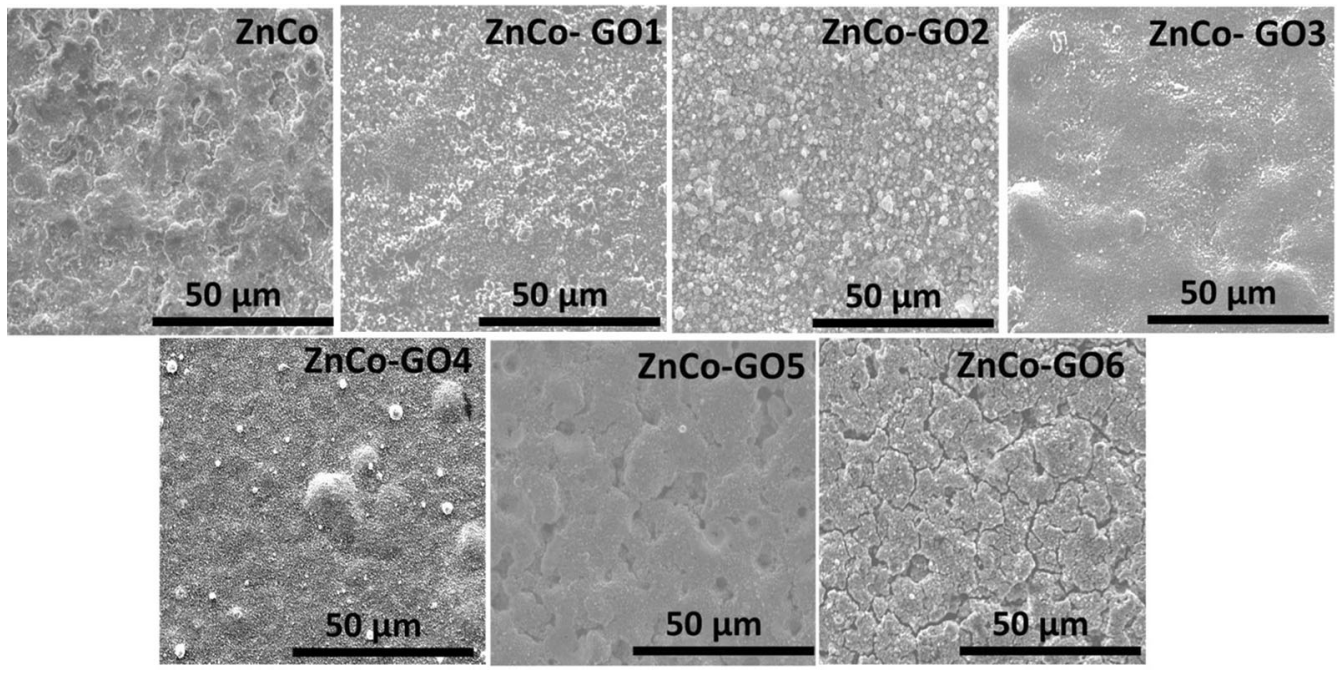

Fig. 2-Low-magnification SEM micrographs of the pristine ZnCo coating and ZnCo-GO composite coatings.

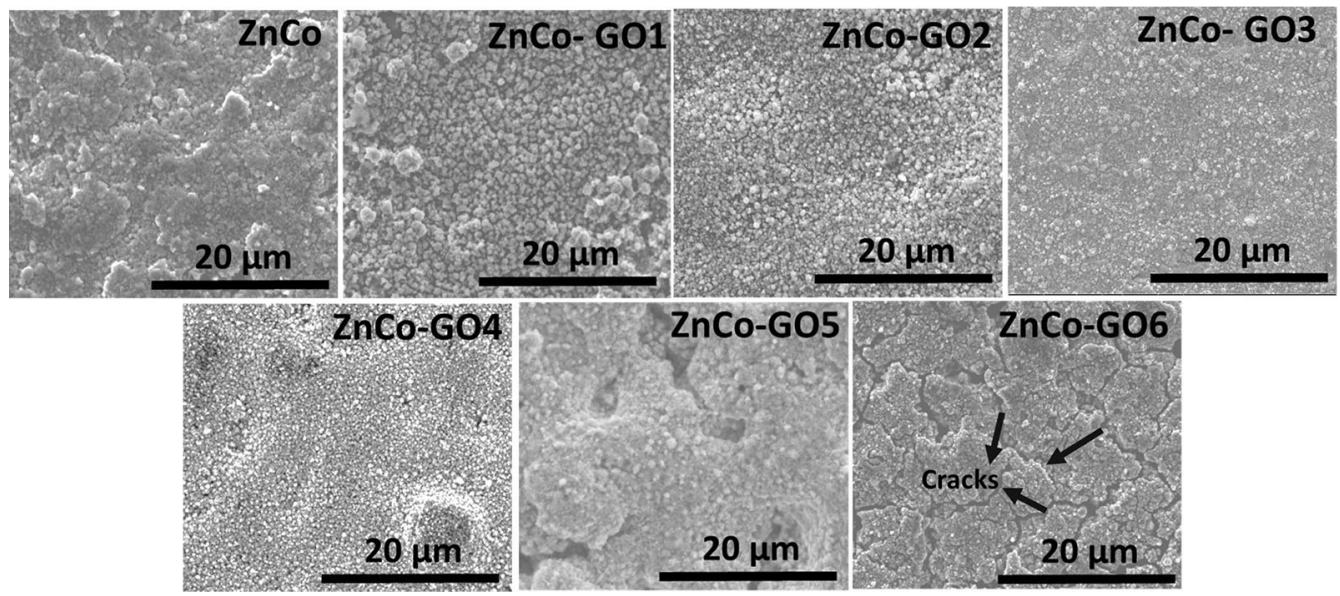

Fig. 3-High-magnification SEM micrographs of the pristine ZnCo coating and ZnCo-GO composite coatings.

most compact morphology. Coating roughness (of macroscopically smooth regions between the cracks) was also measured using AFM analysis. AFM topographic images are provided in Figure 4. The approximate roughness of the pristine $\mathrm{ZnCo}$ was 1 to $2 \mu \mathrm{m}$, of $\mathrm{ZnCo}-\mathrm{GO} 3$ was 80 to $100 \mathrm{~nm}$ and of $\mathrm{ZnCo-GO6}$ was 2 to $3 \mu \mathrm{m}$. AFM results also confirmed that pristine $\mathrm{ZnCo}$ and $\mathrm{ZnCo-GO6}$ coatings have higher surface roughness than the $\mathrm{ZnCo-GO3} \mathrm{coating,} \mathrm{which} \mathrm{is} \mathrm{relatively} \mathrm{compact}$ and smooth. The elemental composition of carbon, zinc and cobalt in the coatings obtained from the EDS analysis is provided in Table II. A gradual increase in the carbon content from $\mathrm{ZnCo-GO1}$ to $\mathrm{ZnCo-GO6}$ qualitatively indicated an increase in the graphene oxide content of the coatings. The incorporation of graphene oxide did not cause a significant change of the relative fraction of $\mathrm{Zn}$ or Co atoms into the coating matrix.

XRD patterns of the pristine $\mathrm{Zn}-\mathrm{Co}$ deposit and $\mathrm{ZnCo-GO}$ deposits are shown in Figure 5. Peaks in the XRD profile revealed the presence of a mixture of $\mathrm{Zn}$ and $\mathrm{Zn}_{10.63} \mathrm{Co}_{2.34}$ intermetallic phases in all the coatings.
All the coatings are (101) textured to the surface. As the amount of graphene-oxide in the electrodeposits increased, the peak intensity of the pure $\mathrm{Zn}$ phase decreased while that of the $\mathrm{Zn}_{10.63} \mathrm{Co}_{2.34}$ phase increased. Addition of the graphene oxide enhanced the volume fraction of the intermetallic phase in the composite coating microstructure.

To understand the evolution of $\mathrm{Zn}$ and intermetallic phases with the addition of graphene oxide, interaction of graphene oxide with $\mathrm{Zn}$ and $\mathrm{Co}$ ions was investigated by zeta potential measurements. Four different electrolytic baths, namely Zn-GO3, Zn-GO6, Co-GO3 and Co-GO6, were prepared. Table III provides the composition of these electrolyte baths. Notably, the bath composition was kept similar with respect to other additives used in case of $\mathrm{ZnCo}$ electrodeposition. Figure 6(a) shows results obtained from the zeta potential measurements of the four different baths. Two important observations can be made from Figure 6(a): (1) irrespective of the concentration of GO, the zeta potential values are always lower for the $\mathrm{Zn}$-containing 

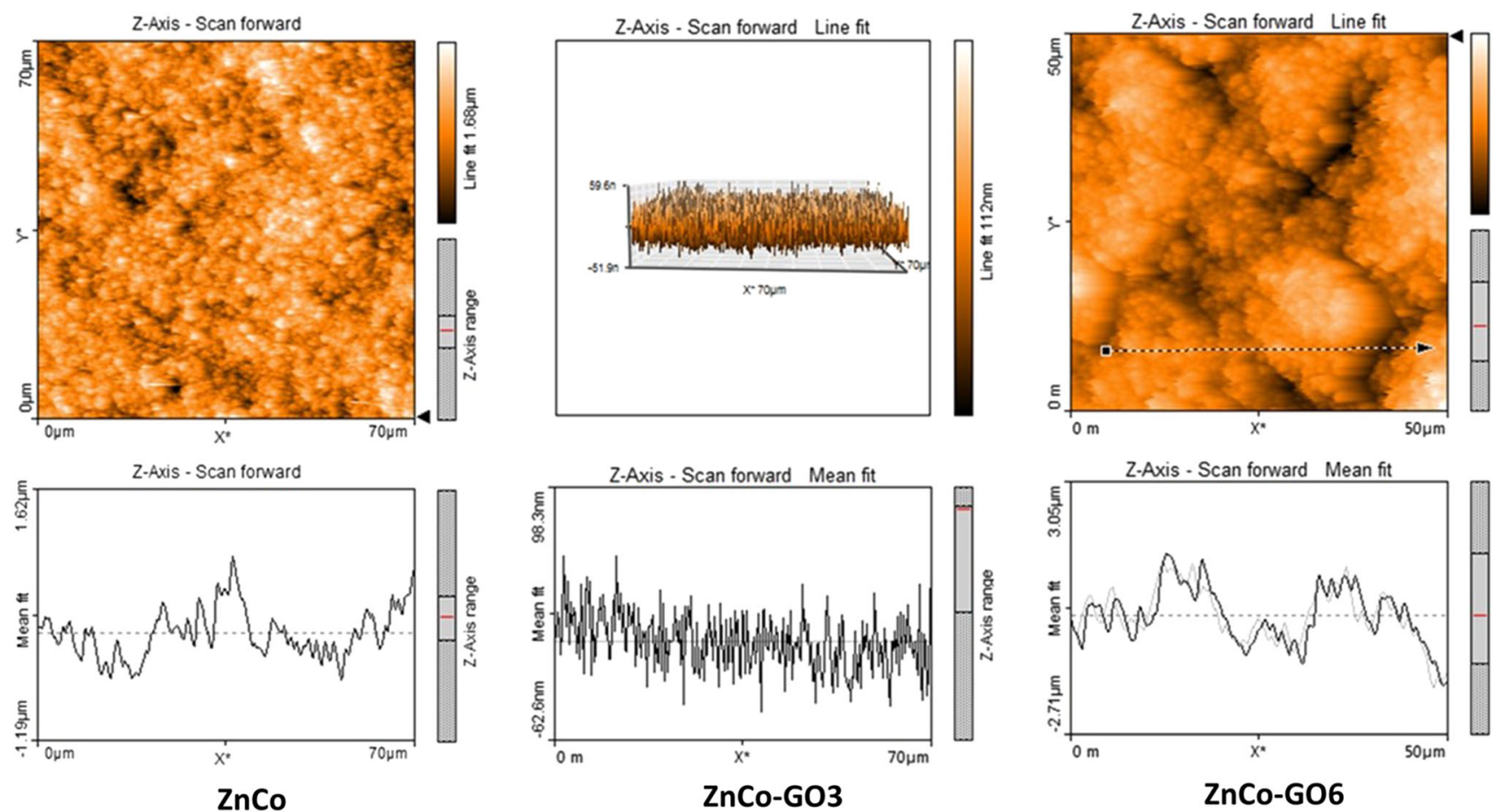

Fig. 4-Representative AFM morphologic image for $\mathrm{ZnCo}$, ZnCo-GO3 and ZnCo-GO6 samples.

Table II. Elemental Composition of ZnCo-GO Composite Coatings Obtained from SEM-EDS Analysis

\begin{tabular}{lccccccc}
\hline Element & ZnCo & ZnCo-GO1 & ZnCo-GO2 & ZnCo-GO3 & ZnCo-GO4 & ZnCo-GO5 & ZnCo-GO6 \\
\hline C (wt pct) & 0 & 2.13 & 3.54 & 3.71 & 4.39 & 5.11 & 5.01 \\
Co (wt pct) & 5.3 & 4.3 & 4.5 & 6.1 & 6.1 & 5.4 & 8.4 \\
Zn (wt pct) & 94.7 & 93.4 & 91.9 & 90.2 & 89.5 & 89.5 & 89.6 \\
\hline
\end{tabular}

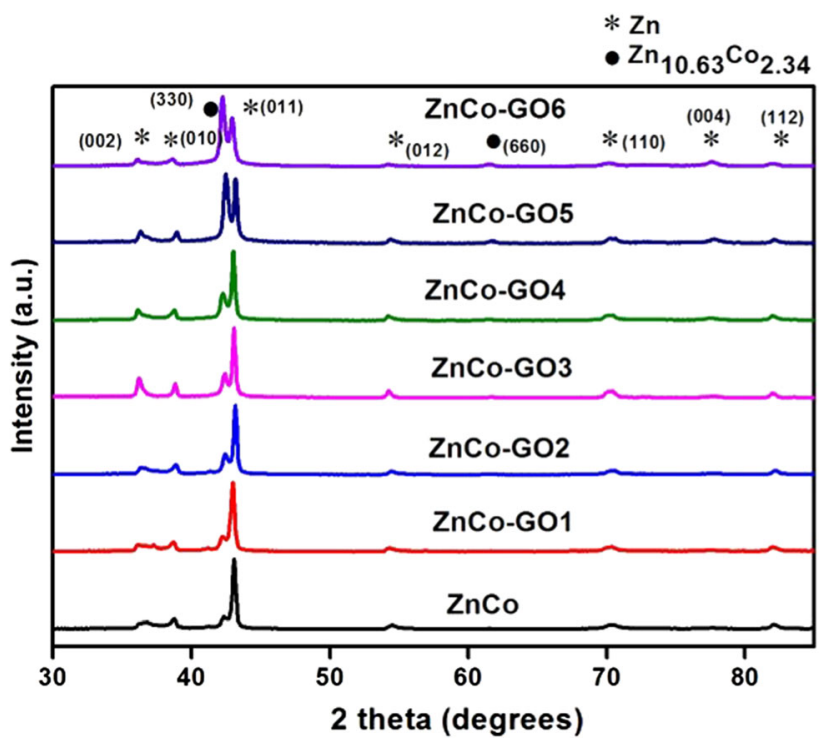

Fig. 5-X-ray diffractograms showing variation of $\mathrm{Zn}$ and $\mathrm{Zn}_{10.63} \mathrm{Co}_{2.34}$ phases in $\mathrm{ZnCo}$ and $\mathrm{ZnCo}-\mathrm{GO}$ coatings.
Table III. Electrolyte Composition Prepared for Zeta Potential and Dynamic Light Scattering

\begin{tabular}{lllll}
\hline Chemicals & Zn-GO3 & Zn-GO6 & Co-GO3 & Co-GO6 \\
\hline $\mathrm{ZnSO}_{4} \cdot 7 \mathrm{H}_{2} \mathrm{O}$ & $150 \mathrm{~g} / \mathrm{L}$ & $150 \mathrm{~g} / \mathrm{L}$ & - & - \\
$\mathrm{CoSO}_{4} \cdot 7 \mathrm{H}_{2} \mathrm{O}$ & - & - & $150 \mathrm{~g} / \mathrm{L}$ & $150 \mathrm{~g} / \mathrm{L}$ \\
$\mathrm{Na}_{2} \mathrm{SO}_{4}$ & $75 \mathrm{~g} / \mathrm{L}$ & $75 \mathrm{~g} / \mathrm{L}$ & $75 \mathrm{~g} / \mathrm{L}$ & $75 \mathrm{~g} / \mathrm{L}$ \\
$\mathrm{CTAB}$ & $0.04 \mathrm{~g} / \mathrm{L}$ & $0.04 \mathrm{~g} / \mathrm{L}$ & $0.04 \mathrm{~g} / \mathrm{L}$ & $0.04 \mathrm{~g} / \mathrm{L}$ \\
\hline
\end{tabular}

electrolyte bath than for the Co containing bath: (2) for both cases the zeta potential decreased with an increase in the amount of GO in the bath. Earlier reports have shown that adsorption of metal ions over GO sheets leads to charge neutralization of the functional groups present on GO resulting in agglomeration and precipitation of metal-GO complexes, which in turn causes a reduction in the observed zeta potential values (absolute values). ${ }^{[30,35]}$ Hence, the zeta potential values in Figure 6(a) indicated that between the $\mathrm{Zn}$ and $\mathrm{Co}$ ions, 


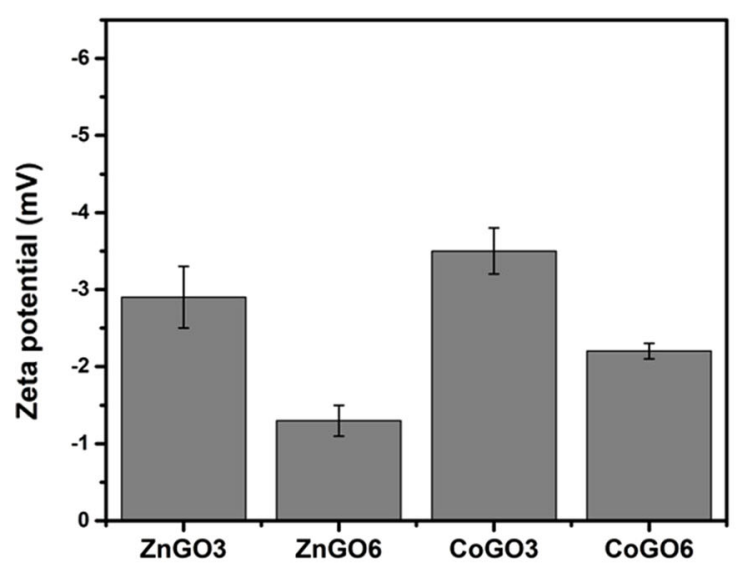

(a)

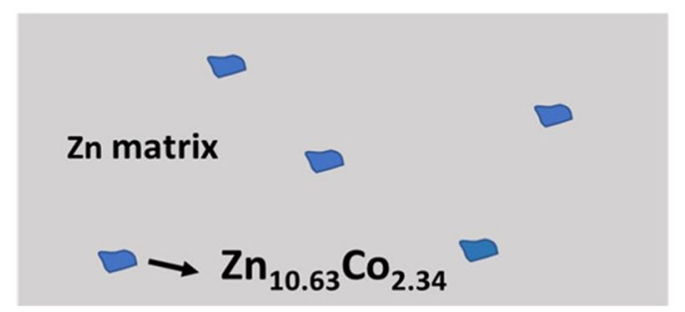

(c)

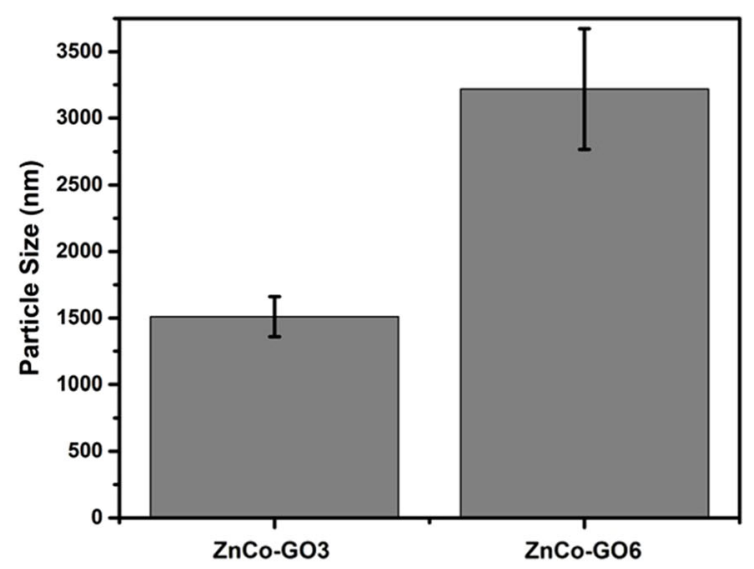

(b)

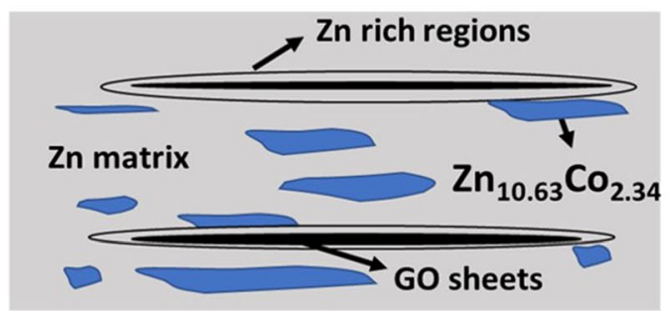

(d)

Fig. 6 - (a) Zeta potential variation for Zn-GO3, Zn-GO6, Co-GO3 and Co-GO6; (b) average particle size for electrolyte ZnCo-GO3 and ZnCo-GO6; $(c, d)$ schematic representation of the electrodeposition mechanism without and with GO, respectively.

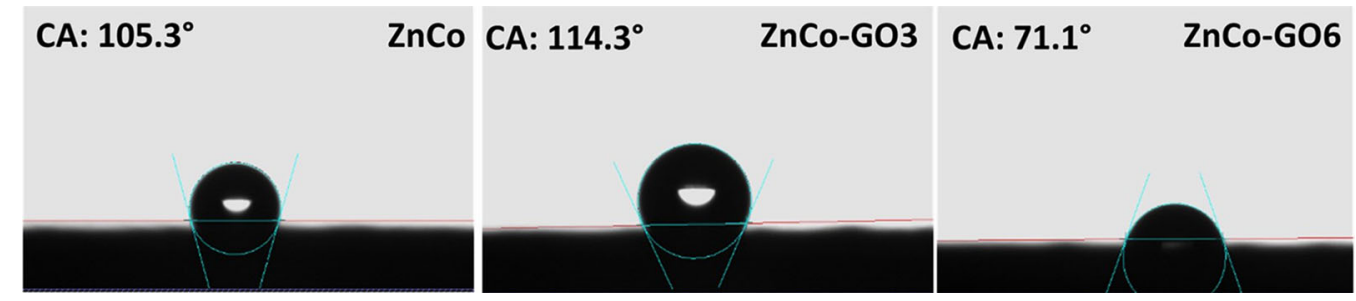

Fig. 7- Contact angle measured from $\mathrm{ZnCo}, \mathrm{ZnCo}-\mathrm{GO} 3$ and $\mathrm{ZnCo}-\mathrm{GO} 6$ coating surfaces.

the graphene oxide sheets have relatively higher affinity toward $\mathrm{Zn}^{+2}$ ions. Dynamic light-scattering (DLS) experiments were conducted to understand the decrease in zeta potential values for higher GO addition. DLS results provided in Figure 6(b) clearly showed that the increase in $\mathrm{GO}$ concentration resulted in an increase in GO agglomerate size from $1510 \pm 150$ to $3220 \pm 453 \mathrm{~nm}$. The zeta potential results strongly indicated that in the electrolyte bath used for the deposition of $\mathrm{ZnCo}-\mathrm{GO}$ composite coatings, $\mathrm{Zn}$ exhibits relatively higher affinity for the GO. In the composite coating microstructure, therefore, regions at and near the GO-metal interface will be relatively richer in $\mathrm{Zn}$, making the matrix regions between the GO sheets relatively richer in Co (according to the schematic presented in Figures 6(c) and (d)). This, according to the
$\mathrm{Zn}$-Co phase diagram, will lead to enhancement of the $\mathrm{Zn}_{10.63} \mathrm{Co}_{2.34}$ intermetallic phase in the coating matrix.

To qualitatively compare the coating surface energy, the contact angle of water droplets was measured over the pristine $\mathrm{ZnCo}, \mathrm{ZnCo}-\mathrm{GO} 3$ and $\mathrm{ZnCo}-\mathrm{GO} 6$ coatings. The value of the contact angle for $\mathrm{ZnCo-GO} 3$ samples was highest at $114.3 \pm 0.8 \mathrm{deg}$ followed by $\mathrm{ZnCo}$ at $105.3 \pm 0.4 \mathrm{deg}$ and $\mathrm{ZnCo}-\mathrm{GO} 6$ at $71.1 \pm 0.7 \mathrm{deg}$, as shown in Figure 7. This indicated the formation of a lower energy surface for the $\mathrm{ZnCo-GO3}$ composite.

\section{Potentiodynamic Polarization and Electrochemical Impedance Spectroscopy (EIS) Studies}

The open circuit potential values of the samples were stabilized to achieve a constant (Figure 8) value before impedance and Tafel measurements. ${ }^{[36]}$ The formation 
of a passivation layer was apparent for the $\mathrm{ZnCo-GO3}$ and $\mathrm{ZnCo-GO} 4$ samples. The corrosion potential $\left(E_{\text {corr }}\right)$, corrosion current density $\left(i_{\text {corr }}\right)$ and Tafel slope $\left(\beta_{\mathrm{c}}\right.$ and $\beta_{\mathrm{a}}$ ) values for the coatings obtained from their respective potentiodynamic polarization curves as shown in Figure 9 (a) are reported in Table IV. The pristine $\mathrm{ZnCo}$ coating showed an $E_{\text {corr }}$ value of

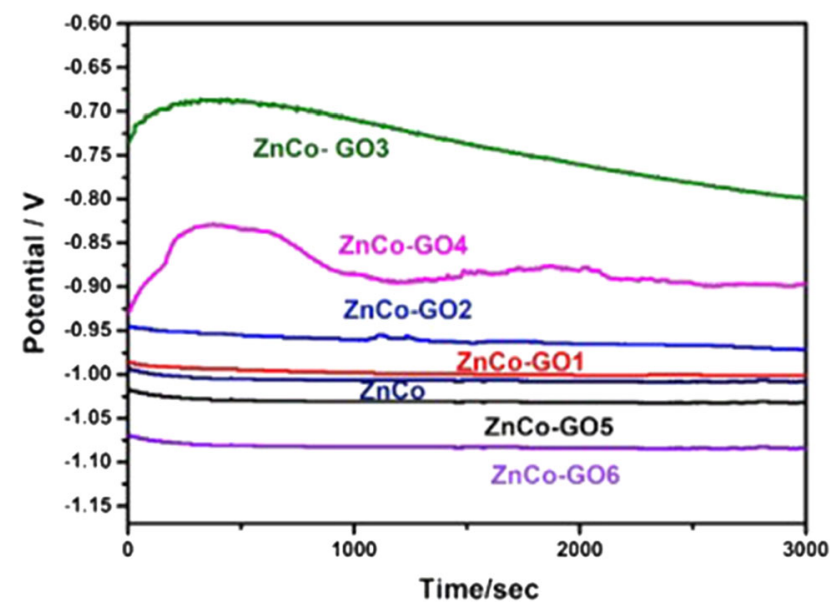

Fig. 8-Open circuit potential curves of $\mathrm{ZnCo}$ and $\mathrm{ZnCo-GO}$ composite coatings.

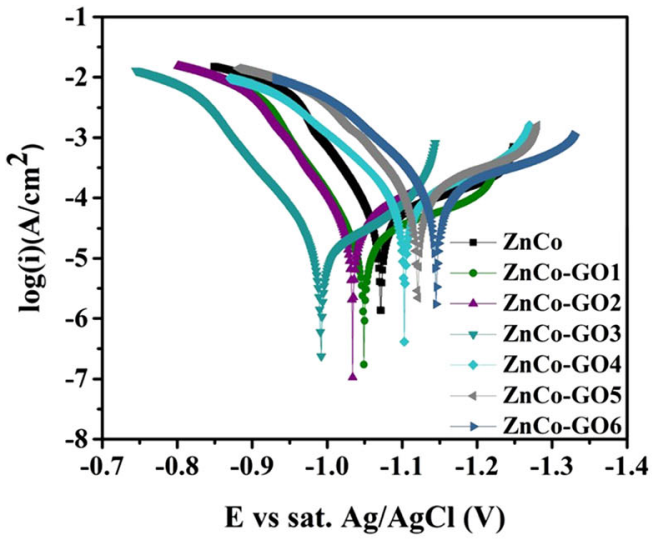

(a)
- $1.091 \mathrm{~V}$. The $E_{\text {corr }}$ of the coatings after graphene oxide addition shifted to positive values for the first three additions. Table IV also shows that the smallest value of $i_{\text {corr }}$ was obtained for the $\mathrm{ZnCo-GO3} \mathrm{sample.} \mathrm{A}$ further increase in the graphene oxide concentration led to a reduction in the corrosion resistance property of the coatings as evident by the decrease in $E_{\text {corr }}$ and increase in $i_{\text {corr }}$ values. Figure 9(b) shows the change in corrosion current density with increasing GO concentration in the composite coatings. A slight passivation behavior was observed in the anodic polarization curve. This indicates the possibility of formation of zinc hydroxide chloride $(\mathrm{ZHC}){ }^{[30]}$

ZnCo alloys exposed to chloride ions have been reported to form $\mathrm{ZHC}^{[4]}$ according to the following reactions:

$$
\begin{aligned}
& 5 \mathrm{Zn}^{+2}(\mathrm{aq})+8 \mathrm{OH}^{-}(\mathrm{aq})+2 \mathrm{Cl}^{-}(\mathrm{aq})+\mathrm{H}_{2} \mathrm{O}(\mathrm{l}) \\
& \quad \rightarrow \mathrm{Zn}_{5}(\mathrm{OH})_{8} \mathrm{Cl}_{2} \cdot \mathrm{H}_{2} \mathrm{O}(\mathrm{s}) .
\end{aligned}
$$

ZHC, because of its low solubility product $\left(10^{-14.2}\right)$, can ensure a higher protection ability for this alloy.

The Nyquist ( $-Z_{\text {img }}$ vs $Z_{\text {real }}$ ) curves obtained from pristine $\mathrm{ZnCo}$ and $\mathrm{ZnCo}-\mathrm{GO}$ composite coatings (from EIS measurements) are shown in Figures 10(a) and (b). Symbols in the curve represent simulated data, and the lines represent the measured data.

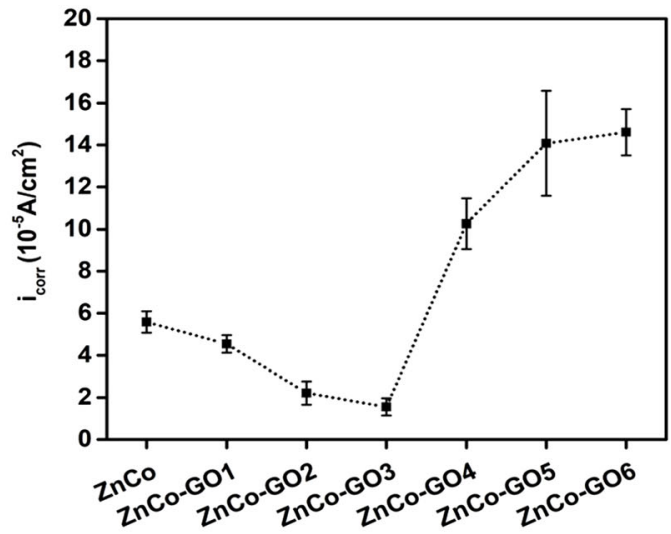

(b)

Fig. 9-(a) Tafel polarization curves of $\mathrm{ZnCo}$ and $\mathrm{ZnCo}-\mathrm{GO}$ composite coatings; $(b)$ corrosion current density values plotted for ZnCo and ZnCo-GO composite coatings.

Table IV. Corrosion Current Density $\left(i_{\text {corr }}\right)$, Corrosion Potential $\left(E_{\text {corr }}\right), \beta_{\mathrm{c}}$ and $\beta_{\mathrm{a}}$ Values Obtained from Potentiodynamic Polarization Tests

\begin{tabular}{lcccc}
\hline Sample ID & $E_{\text {corr }}(\mathrm{V})$ & $i_{\text {corr }}\left(10^{-5} \mathrm{~A} / \mathrm{cm}^{2}\right)$ & $\beta_{\mathrm{c}}$ & $\beta_{\mathrm{a}}$ \\
\hline ZnCo & $-1.077 \pm 0.031$ & $5.58 \pm 0.51$ & $4.13 \pm 2.12$ & $16.22 \pm 5.3$ \\
ZnCo-GO1 & $-1.053 \pm 0.012$ & $4.54 \pm 0.42$ & $5.40 \pm 3.22$ & $15.56 \pm 4.4$ \\
ZnCo-GO2 & $-1.037 \pm 0.011$ & $2.21 \pm 0.56$ & $4.27 \pm 1.42$ & $17.03 \pm 2.2$ \\
ZnCo-GO3 & $-0.995 \pm 0.023$ & $1.55 \pm 0.41$ & $8.82 \pm 1.25$ & $14.61 \pm 3.4$ \\
ZnCo-GO4 & $-1.105 \pm 0.013$ & $10.26 \pm 1.2$ & $5.56 \pm 5.5$ & $12.06 \pm 1.4$ \\
ZnCo-GO5 & $-1.124 \pm 0.023$ & $14.08 \pm 2.5$ & $4.33 \pm 1.4$ & $11.31 \pm 5.2$ \\
ZnCo-GO6 & $-1.150 \pm 0.019$ & $14.61 \pm 1.1$ & $3.89 \pm 2.42$ & $11.28 \pm 2.1$ \\
\hline
\end{tabular}




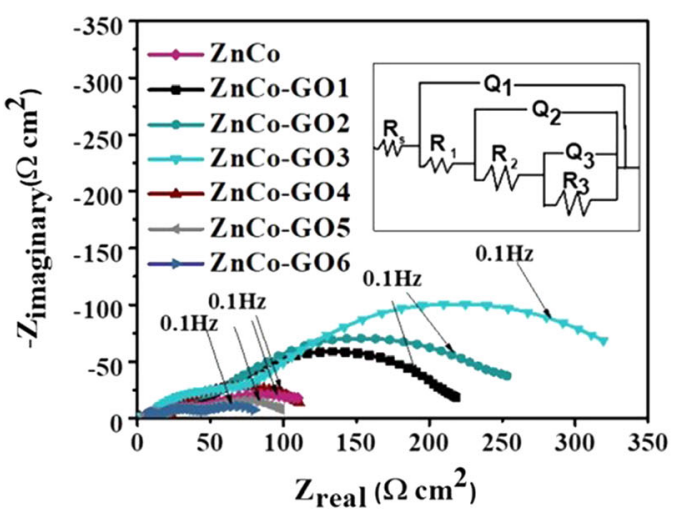

(a)

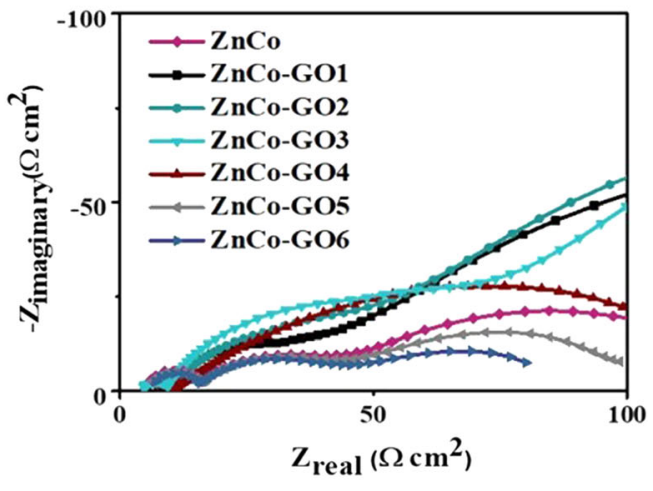

(b)

Fig. 10 - (a) Nyquist plots for ZnCo and ZnCo-GO coatings. Inset: EEC used for circuit parameter calculations; (b) Nyquist plot showing high-frequency region only.

The Nyquist plot in Figures 10(a) and (b) shows three capacitive loops for $\mathrm{ZnCo}$ as well as $\mathrm{ZnCo-GO}$ composites. The low-frequency response corresponds to $\mathrm{O}_{2}$ reduction at the coating/electrolyte interface leading to the formation of the corrosion products, ${ }^{[1,4]}$ while, the medium- and high-frequency region semicircles could be associated with charge transfer resistance and oxide layer pore resistance, respectively. To simulate the metal/solution interface, the Nyquist plots were fitted using an electrical equivalent circuit (EEC) model as shown in the Figure 10(a) inset with the help of Zsimp win 3.21 software. A constant phase element (CPE) ' $Q$ ' was used in place of the capacitance element to include contributions for electrode porosity, surface roughness and variation in the coating composition leading to non-uniform potential and current distribution. The impedance $\left(Z_{\mathrm{CPE}}\right)$ corresponding to this element " $Q$ " is defined as:

$$
Z_{\mathrm{CPE}}=1 / Q(j \omega)^{n}
$$

where $0 \leq \leq 1$. For $n=0$, the $Q$ value corresponds to a resistance; for $n=1$, a capacitance; for $n=0.5$, a Warburg element. $\omega=2 \pi f$ (where $f=$ frequency), and $j$ is an imaginary unit.

The impedance parameters obtained from the equivalent circuit are provided in Table V. The errors associated with the circuit elements were $\leq 10$ pct. In EEC, $R_{\mathrm{S}}$ represents solution resistance between working the electrode and reference electrode (the distance between the starting point of the semi-circle and the origin in the Nyquist plot). The resistance contribution due to the high-frequency region is marked as $R_{1}$, and the corresponding capacitance is $Q_{1} . R_{2}$ and $Q_{2}$ correspond to the mid-frequency region depicting the charge transfer resistance and double-layer capacitance, respectively. The low frequency contribution is depicted as $R_{3}$ and $Q_{3}$ representing the electrochemical process at the electrode surface, likely involving the oxidation-reduction process of the corrosion products formed. The overall corrosion resistance is expressed as polarization resistance $\left(R_{\mathrm{p}}\right)$ and defined as $R_{\mathrm{p}}=R_{1}+R_{2}+R_{3}$ in Table V. Figure 10(a) shows that for the first three GO additions, the diameter of the capacitive loops increases with the amount of graphene oxide in the $\mathrm{ZnCo}$ coatings. This is also reflected in the values of polarization resistance reported in Table V. For the $\mathrm{ZnCo-GO3}$ coating, the value of $R_{\mathrm{p}}$ increased to $370.13 \Omega \mathrm{cm}^{2}$ from the $147.51 \Omega \mathrm{cm}^{2}$ observed without graphene oxide addition. Further addition of GO beyond $\mathrm{ZnCo-GO} 3$ led to a decrease in the value of $R_{\mathrm{p}}$ to $70.62 \Omega \mathrm{cm}^{2}$ for the ZnCo-GO6 coating. Also, the double layer capacitance of the coatings with GO3 addition showed the lowest values.

This trend was similar to the corrosion current density trend observed in the Tafel polarization curve (Figure 9(b)). The increase in the polarization resistance $\left(R_{\mathrm{p}}\right)$ values on graphene oxide incorporation indicates reduced surface activity of the coatings toward electroactive media and a reduced double-layer formation. However, for the coating with more GO (e.g., the ZnCo-GO6 coating), the observed decrease in the $R_{\mathrm{p}}$ value can be attributed to the GO agglomeration in the electroplating bath leading to increased surface roughness. This is also evident in the values of frequency dispersion factor ' $n$ ' obtained for these coatings. A low ' $n$ ' value as observed for ZnCo-GO6 $(n=0.58)$ usually corresponds to high roughness or a heterogeneous surface. The observed electrochemical behavior substantiates the morphologic characteristics revealed in the SEM micrographs as shown in Figure 3. Hence, it can be concluded that $\mathrm{GO} 3(0.4 \mathrm{~g} / \mathrm{L})$ is the optimum concentration of graphene oxide that can be added to a $\mathrm{ZnCo}$ system for achieving the best corrosion resistance performance.

The pristine $\mathrm{ZnCo}$, $\mathrm{ZnCo-GO3}$ and $\mathrm{ZnCo-GO6}$ samples were exposed to $3.5 \mathrm{wt}$ pct sodium chloride solution for 24 and 48 hours, and their impedance behavior was recorded as Nyquist plots. Figures 11(a) and (b) shows the Nyquist plots for 24 hours exposure, and Figures 11(c) and (d) depicts Nyquist plots for 48 hours exposure. The impedance parameters obtained after using $R(Q(R(Q(R(Q R)))))$ as the EEC circuit are mentioned in Tables VI and VII. Table VI shows that, for the $\mathrm{ZnCo-GO} 3$ sample, 24 hours immersion in the 
Table V. $Q_{\mathrm{dl}}, R_{\mathrm{p}}, n$ and $\chi^{2}$ Values Obtained from Electrical Equivalent Circuit Simulations of the EIS Data

\begin{tabular}{|c|c|c|c|c|c|c|c|c|c|c|c|c|}
\hline Sample ID & $\begin{array}{l}\text { Electrolyte } \\
\text { Resistance } R_{\mathrm{s}} \\
\quad\left(\Omega \mathrm{cm}^{2}\right)\end{array}$ & $\begin{array}{c}R_{1} \\
\left(\Omega \mathrm{cm}^{2}\right)\end{array}$ & $\begin{array}{c}Q_{1} \\
(\mu \mathrm{F} / \\
\left.\mathrm{cm}^{2}\right)\end{array}$ & $n_{1}$ & $\begin{array}{c}R_{2} \\
\left(\Omega \mathrm{cm}^{2}\right)\end{array}$ & $\begin{array}{c}Q_{2} \\
(\mu \mathrm{F} / \\
\left.\mathrm{cm}^{2}\right)\end{array}$ & $n_{2}$ & $\begin{array}{c}R_{3} \\
\left(\Omega \mathrm{cm}^{2}\right)\end{array}$ & $\begin{array}{c}Q_{3} \\
(\mu \mathrm{F} / \\
\left.\mathrm{cm}^{2}\right)\end{array}$ & $n_{3}$ & $\begin{array}{l}\text { Polarization } \\
\text { Resistance } R_{\mathrm{p}} \\
\quad\left(\Omega \mathrm{cm}^{2}\right)\end{array}$ & $\left(\begin{array}{c}\chi^{2} \\
\left(\times 10^{-3}\right)\end{array}\right.$ \\
\hline $\mathrm{ZnCo}$ & 5.203 & 15.7 & 122.3 & 0.89 & 30.51 & 70.32 & 0.81 & 101.3 & 98 & 0.76 & 147.51 & 8.52 \\
\hline $\mathrm{ZnCo}-\mathrm{GO} 1$ & 5.239 & 12.3 & 102.4 & 0.8 & 37.2 & 65.12 & 0.76 & 176.3 & 94 & 0.66 & 225.8 & 3.2 \\
\hline $\mathrm{ZnCo}-\mathrm{GO} 2$ & 4.945 & 12.02 & 101.3 & 0.88 & 65.2 & 35.45 & 0.87 & 198.68 & 92 & 0.62 & 275.9 & 2.72 \\
\hline $\mathrm{ZnCo}-\mathrm{GO} 3$ & 6.968 & 16.3 & 84.1 & 0.84 & 78.93 & 37.3 & 0.92 & 274.9 & 79 & 0.91 & 370.13 & 6.60 \\
\hline $\mathrm{ZnCo}-\mathrm{GO} 4$ & 6.578 & 3.33 & 93.84 & 0.71 & 22.92 & 90.12 & 0.82 & 103.95 & 121 & 0.73 & 130.2 & 1.38 \\
\hline $\mathrm{ZnCo}-\mathrm{GO} 5$ & 5.812 & 10.74 & 70.38 & 0.62 & 43.2 & 75.22 & 0.68 & 56.29 & 131 & 0.65 & 110.23 & 1.26 \\
\hline ZnCo-GO6 & 4.747 & 20.1 & 99.52 & 0.6 & 25.5 & 98.7 & 0.57 & 25.02 & 130 & 0.58 & 70.62 & 1.11 \\
\hline
\end{tabular}

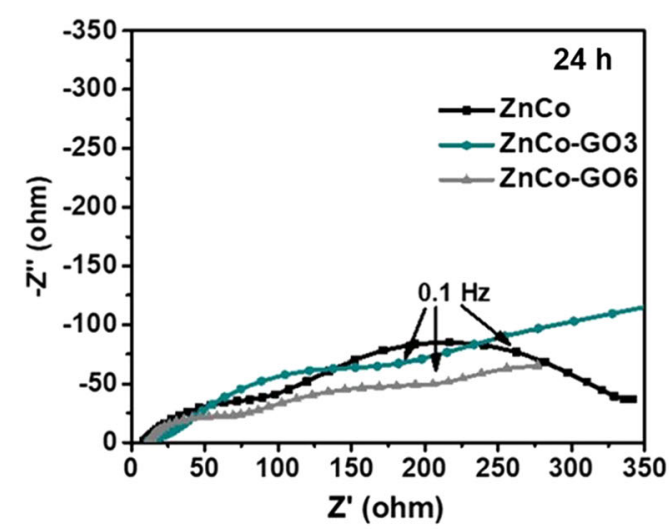

(a)

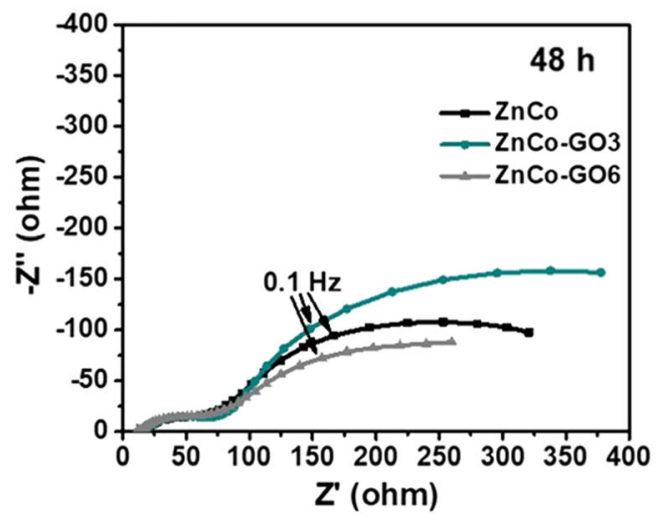

(c)

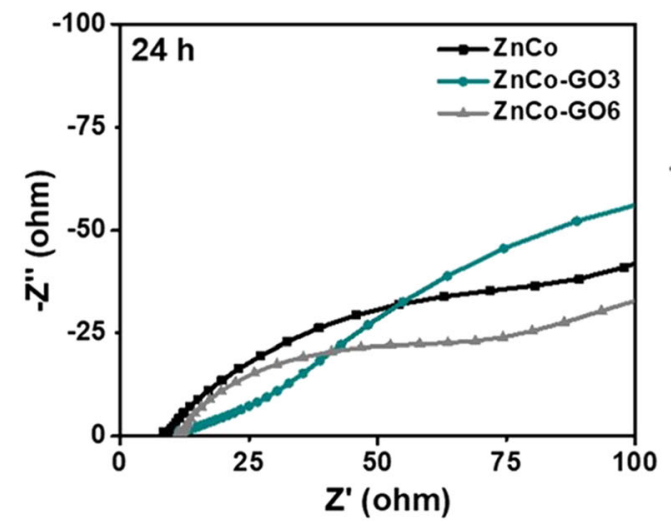

(b)

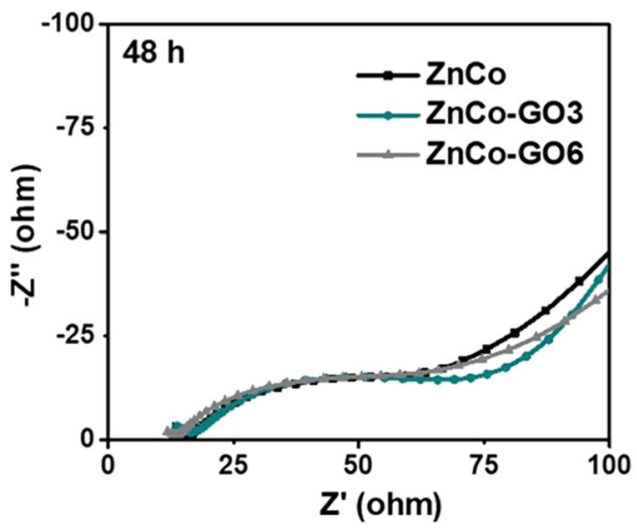

(d)

Fig. 11-(a) Nyquist plot for $24 \mathrm{~h}$ exposure of ZnCo, ZnCo-GO3 and ZnCo-GO6 coatings to 3.5 wt pct NaCl solution; (c) Nyquist plot for $48 \mathrm{~h}$ exposure of $\mathrm{ZnCo}, \mathrm{ZnCo}-\mathrm{GO} 3$ and $\mathrm{ZnCo}-\mathrm{GO} 6$ coatings to $3.5 \mathrm{wt}$ pet $\mathrm{NaCl}$ solution; $(b, d)$ represents high-frequency Nyquist regions for 24 and $48 \mathrm{~h}$ exposure, respectively.

Table VI. Optimum Fit Parameters for ZnCo, ZnCo-GO3 and ZnCo-GO6 for 24 h Immersion Time

\begin{tabular}{|c|c|c|c|c|c|c|c|c|c|c|c|c|}
\hline Sample ID & $\begin{array}{l}\text { Electrolyte } \\
\text { Resistance } R_{\mathrm{s}} \\
\quad\left(\Omega \mathrm{cm}^{2}\right)\end{array}$ & $\begin{array}{c}R_{1} \\
\left(\Omega \mathrm{cm}^{2}\right)\end{array}$ & $\begin{array}{c}Q_{1} \\
(\mu \mathrm{F} / \\
\left.\mathrm{cm}^{2}\right)\end{array}$ & $n_{1}$ & $\begin{array}{c}R_{2} \\
\left(\Omega \mathrm{cm}^{2}\right)\end{array}$ & $\begin{array}{c}Q_{2} \\
(\mu \mathrm{F} / \\
\left.\mathrm{cm}^{2}\right)\end{array}$ & $n_{2}$ & $\begin{array}{c}R_{3} \\
\left(\Omega \mathrm{cm}^{2}\right)\end{array}$ & $\begin{array}{c}Q_{3} \\
(\mu \mathrm{F} / \\
\left.\mathrm{cm}^{2}\right)\end{array}$ & $n_{3}$ & $\begin{array}{l}\text { Polarization } \\
\text { Resistance } R_{\mathrm{p}} \\
\quad\left(\Omega \mathrm{cm}^{2}\right)\end{array}$ & $\left(\times \frac{\chi^{2}}{\left(0^{-3}\right)}\right.$ \\
\hline $\mathrm{ZnCo}$ & 11.59 & 30.85 & 134.8 & 0.86 & 92.7 & 394.8 & 0.85 & 241.5 & 235.2 & 0.86 & 365.05 & 6.23 \\
\hline $\mathrm{ZnCo}-\mathrm{GO} 3$ & 7.402 & 85.5 & 92.62 & 1 & 209.4 & 261.1 & 0.90 & 258.8 & 236.6 & 0.96 & 553.7 & 4.93 \\
\hline ZnCo-GO6 & 10.86 & 54.86 & 193.3 & 0.40 & 170.2 & 590.4 & 0.73 & 96.18 & 535.2 & 0.53 & 321.24 & 1.42 \\
\hline
\end{tabular}


electroactive media leads to an increase in the $R_{1}$ value and a corresponding decrease in the $Q_{1}$ value representing decreased porosity of the oxide layer. Also, for 24 hours immersion, an increase in polarization resistance values was observed for all three coatings, probably due to the formation of a stable oxide layer. In Tables VI and VII, for the CPE exponent, ' $n$ ' values between 0.5 and 0.8 ( $\mathrm{ZnCo}-\mathrm{GO} 6)$ represent uneven charge distribution over the electrode surface. This may be attributed to greater surface roughness and smaller grain sizes leading to large grain boundary area. ' $n$ ' values $>0.85(\mathrm{ZnCo}-\mathrm{GO} 3)$ represent almost ideal capacitive behavior. All the observations indicate that the $\mathrm{ZnCo-GO} 3$ has the maximum impedance value for 24 hours as well as 48 hours exposure to the electroactive media.

\section{DISCUSSION}

The following key observations were made: (1) the corrosion rate of the composite coatings is sensitive to the amount of graphene oxide contained in the coatings, and among all the coatings, $\mathrm{ZnCo-GO} 3$ yielded the minimum corrosion rate while the corrosion rate of $\mathrm{ZnCo-GO6}$ was highest and even higher than that of the pristine $\mathrm{ZnCo}$ coating; (2) the coating smoothness increased till $\mathrm{ZnCo}-\mathrm{GO} 3$ and then degraded with the formation of cracks for further addition of graphene oxide into the coating.
To understand the effect of phase constitution on the corrosion behavior of the coatings, a pristine $\mathrm{ZnCo}$ coating and coatings containing only $\mathrm{Zn}_{10.63} \mathrm{Co}_{2.34}$ intermetallic phase were exposed to the corrosive medium, and the weight loss method was used to estimate the extent of degradation. A coating containing only $\mathrm{Zn}_{10.63} \mathrm{Co}_{2.34}$ intermetallic phase was obtained. A higher amount of CTAB and cobalt concentration in the electrolytic bath was used for producing this intermetallic coating. Representative low- and high-magnification SEM micrographs depicting morphologic characteristics of the $\mathrm{Zn}_{10.63} \mathrm{Co}_{2.34}$ intermetallic coatings are provided in Figure 12(a). The XRD pattern obtained from the coating showing only a $\mathrm{Zn}_{10.63} \mathrm{Co}_{2.34}$ phase peak is provided in Figure 12(b). Results from the weight loss measurement are provided in Figure 13.

The intermetallic phase is clearly more resistant to the corrosive attack than the $\mathrm{ZnCo}$ solid solution phase (primarily present in the pristine $\mathrm{ZnCo}$ coating). Coatings with higher intermetallic phase constitution should therefore exhibit higher anti-corrosive performance. According to this observation, corrosion resistance of the $\mathrm{ZnCo-GO}$ coatings should monotonically increase with an increase in the GO content as it leads to enhancement of the intermetallic phase fraction. It is therefore speculated that an increase in the volume fraction of the intermetallic phase facilitated enhancement of the corrosion resistance of the composite coatings for the initial GO amounts. The said effect was not dominant in the case of higher $\mathrm{GO}$ additions in the coatings as evident by the increase in the corrosion

Table VII. Optimum Fit Parameters for ZnCo, ZnCo-GO3 and ZnCo-GO6 for 48 h Immersion Time

\begin{tabular}{|c|c|c|c|c|c|c|c|c|c|c|c|c|}
\hline Sample ID & $\begin{array}{l}\text { Electrolyte } \\
\text { Resistance } R_{\mathrm{s}} \\
\left(\Omega \mathrm{cm}^{2}\right)\end{array}$ & $\begin{array}{c}R_{1} \\
\left(\Omega \mathrm{cm}^{2}\right)\end{array}$ & $\begin{array}{c}Q_{1} \\
(\mu \mathrm{F} / \\
\left.\mathrm{cm}^{2}\right)\end{array}$ & $n_{1}$ & $\begin{array}{c}R_{2} \\
\left(\Omega \mathrm{cm}^{2}\right)\end{array}$ & $\begin{array}{c}Q_{2} \\
(\mu \mathrm{F} / \\
\left.\mathrm{cm}^{2}\right)\end{array}$ & $n_{2}$ & $\begin{array}{c}R_{3} \\
\left(\Omega \mathrm{cm}^{2}\right)\end{array}$ & $\begin{array}{c}Q_{3} \\
(\mu \mathrm{F} / \\
\left.\mathrm{cm}^{2}\right)\end{array}$ & $n_{3}$ & $\begin{array}{l}\text { Polarization } \\
\text { Resistance } R_{\mathrm{p}} \\
\quad\left(\Omega \mathrm{cm}^{2}\right)\end{array}$ & $\left(\begin{array}{c}\chi^{2} \\
\left(\times 10^{-3}\right)\end{array}\right.$ \\
\hline $\mathrm{ZnCo}$ & 10.68 & 14.46 & 450 & 0.85 & 57.9 & 43.79 & 0.81 & 300.1 & 437 & 0.83 & 372.46 & 1.75 \\
\hline $\mathrm{ZnCo}-\mathrm{GO} 3$ & 6.60 & 10.44 & 44.59 & 0.78 & 65.2 & 533.1 & 0.56 & 449.1 & 479 & 0.87 & 524.82 & 3.50 \\
\hline $\mathrm{ZnCo-GO6}$ & 7.93 & 5.381 & 281 & 0.75 & 55.9 & 551.7 & 0.59 & 277.7 & 1037 & 0.54 & 339.04 & 2.81 \\
\hline
\end{tabular}

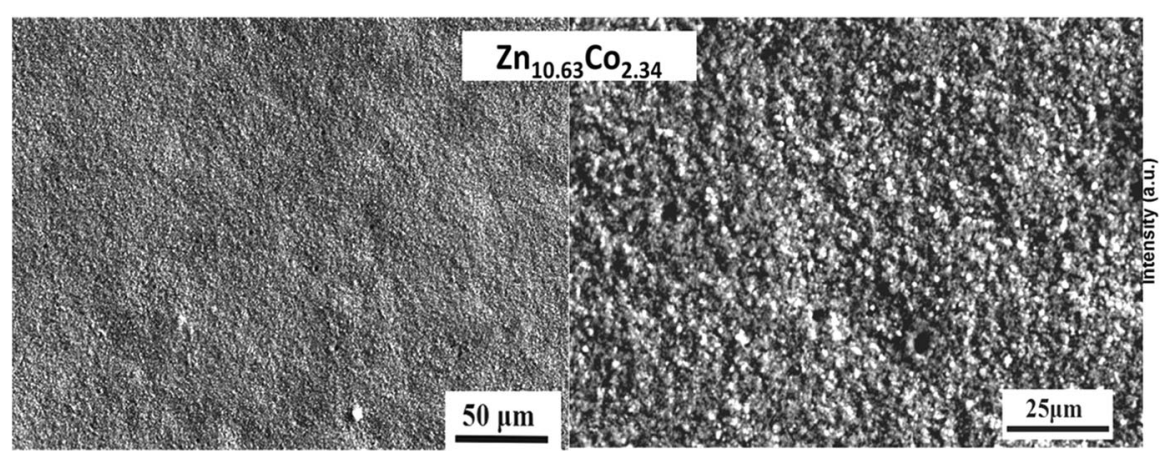

(a)

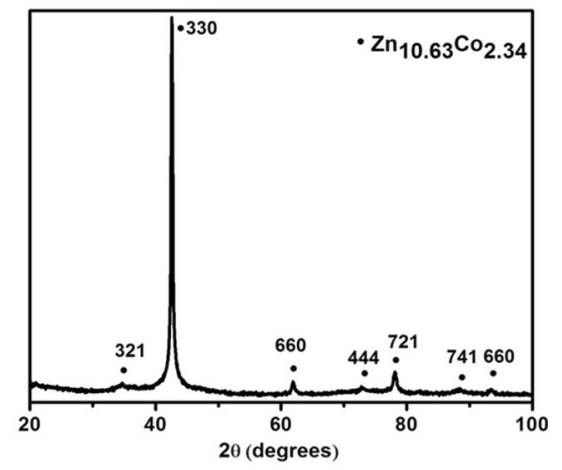

(b)

Fig. 12- $(a, b)$ SEM scan and XRD micrographs of only the $\mathrm{Zn}_{10.63} \mathrm{Co}_{2.34}$ phase coating. 
rate beyond the $\mathrm{ZnCo-GO3}$ coating. The observed enhancement of the corrosion rate of the coatings beyond the $\mathrm{ZnCo-GO} 3$ coating was possibly due to degradation of the surface morphology, as observed in the SEM micrographs and AFM analysis of coatings with higher amounts of graphene oxide (Figures 2, 3, and 4).

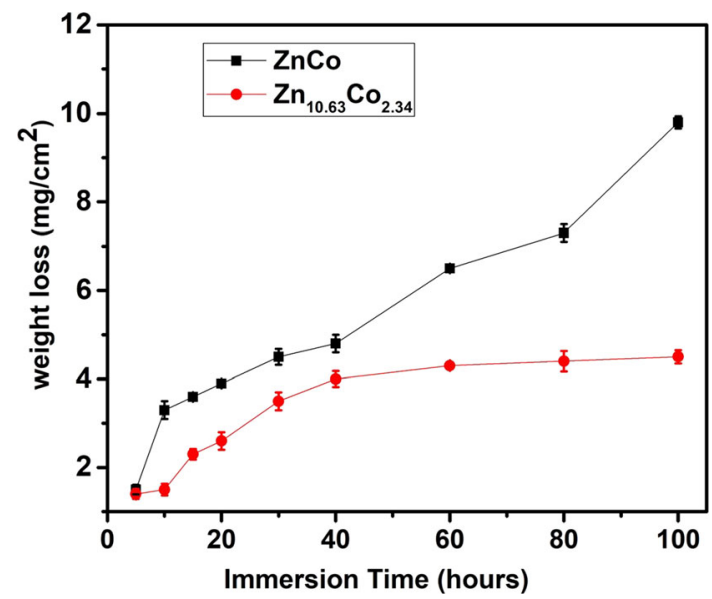

Fig. 13-Weight loss values obtained for $\mathrm{ZnCo}$ and $\mathrm{Zn}_{10.63} \mathrm{Co}_{2.34}$ samples as a function of time.
An increase in the carbon content together with degradation in the surface morphology indicated non-uniform deposition of agglomerated graphene oxide in the coating matrix. This was confirmed by the compositional line scan analysis of the distribution of carbon content of the coatings. The carbon compositional line scans obtained from $\mathrm{ZnCo}, \mathrm{ZnCo}-\mathrm{GO} 3$ and ZnCo-GO6 coatings are shown in Figure 14. The carbon profile for $\mathrm{ZnCo}$ defines the "baseline" carbon content, which is essentially due to carbon other than from the graphene oxide. The composition profile for $\mathrm{ZnCo-GO3}$ is above the "baseline" and is smooth, indicating the presence and uniform distribution of graphene oxide in the coating matrix. The composition profile for the $\mathrm{ZnCo-GO6}$ coatings is expectedly the highest above the "baseline" and is also relatively rough, which confirmed the non-uniform distribution of graphene oxide in the $\mathrm{ZnCo-GO6}$ coating matrix.

The XRD diffractogram of $\mathrm{ZnCo-GO} 3$ and ZnCo-GO6 coatings after 24 hours exposure to 3.5 wt pet $\mathrm{NaCl}$ solution is shown in Figures 15(b) and (a), respectively. The diffraction peaks corresponding to $\left[\mathrm{Zn}_{5}(\mathrm{OH})_{8} \mathrm{Cl}_{2} \cdot \mathrm{H}_{2} \mathrm{O}\right](\mathrm{ZHC})$, zinc oxide $(\mathrm{ZnO})$ and cobalt oxide $\left(\mathrm{Co}_{2.83} \mathrm{O}_{4}\right)$ were observed in both cases. Smoother morphology and optimum GO content in $\mathrm{ZnCo-GO3}$ led to stability and adherence of the corrosion product, which contributed to higher corrosion resistance performance. To again compare the stability of the
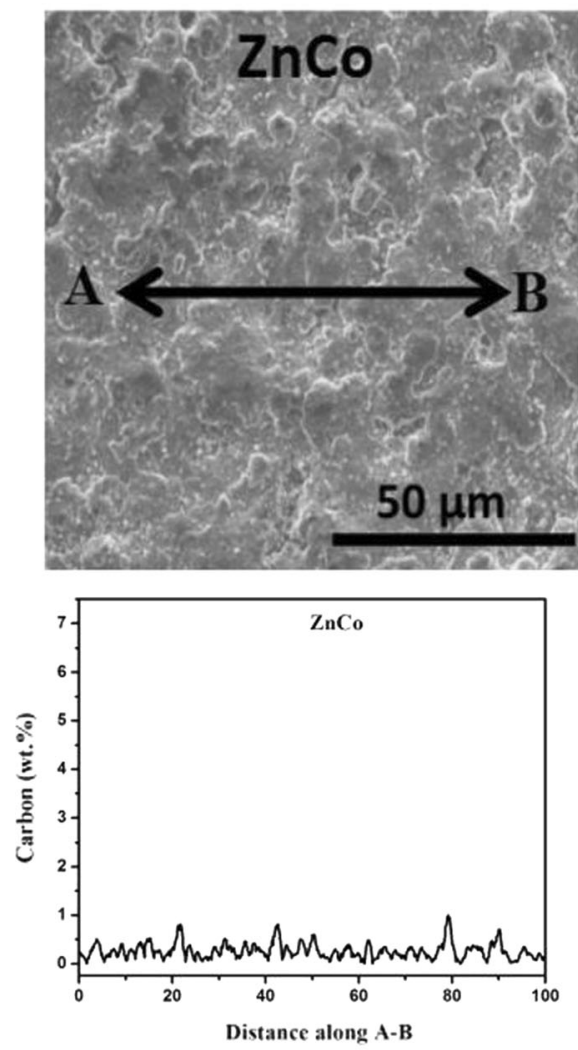

(a)
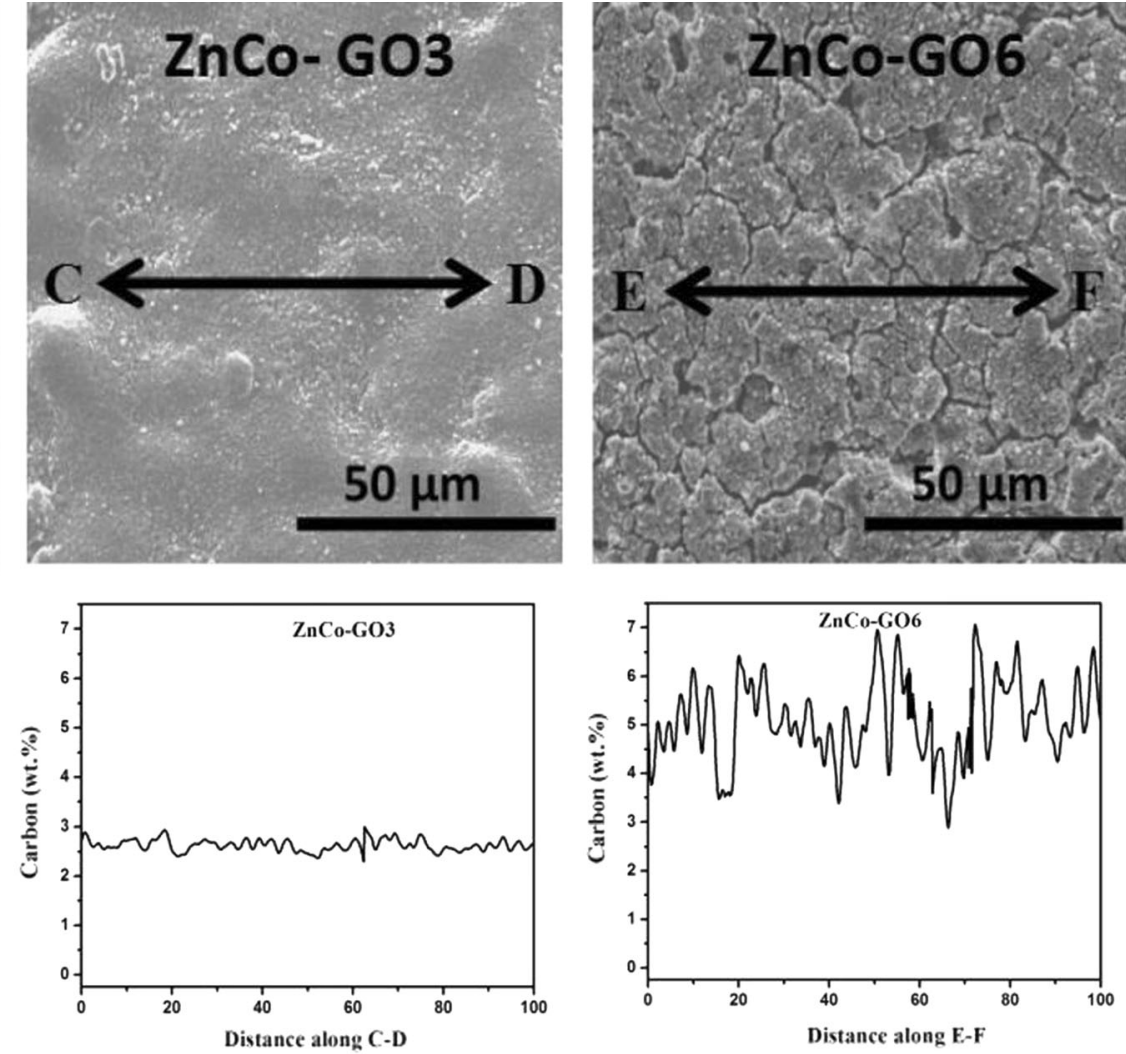

(b)

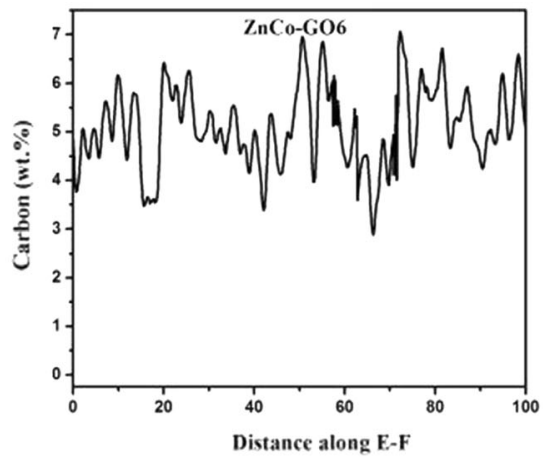

(c)

Fig. 14 - SEM micrographs and compositional line scan profile showing the distribution of carbon inside the $\mathrm{ZnCo}$, $\mathrm{ZnCo-GO3} \mathrm{and} \mathrm{ZnCo-GO6}$ composite coatings. 


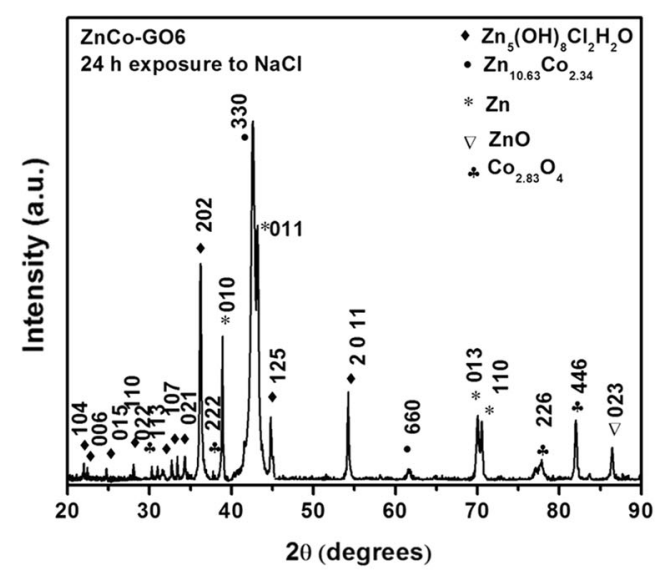

(a)

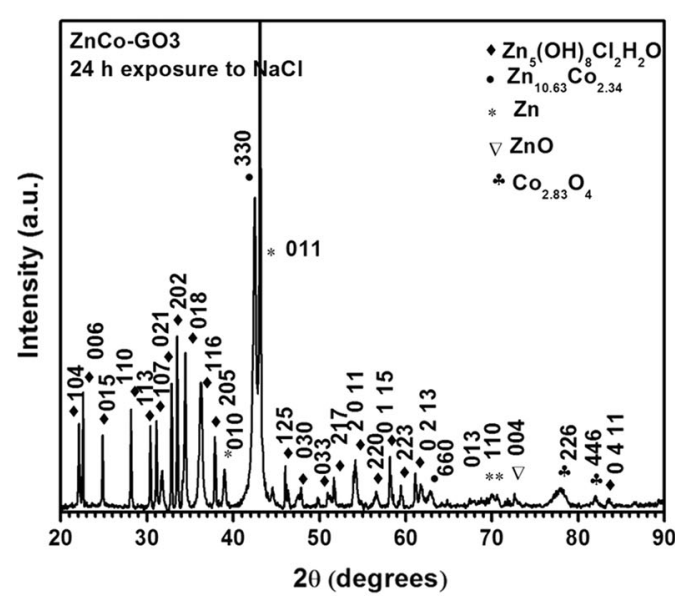

(b)

Fig. 15- $(a, b)$ XRD diffractograms of ZnCo-GO6 and ZnCo-GO3 samples after 24 h exposure to 3.5 wt pct $\mathrm{NaCl}$ solution.

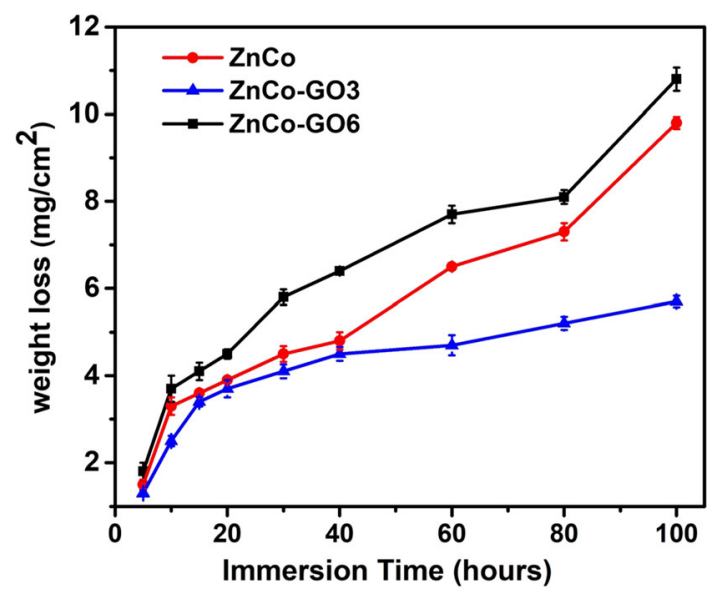

Fig. 16-Weight loss values obtained for $\mathrm{ZnCo}, \mathrm{ZnCo-GO} 3$ and ZnCo-GO6 samples as a function of time.

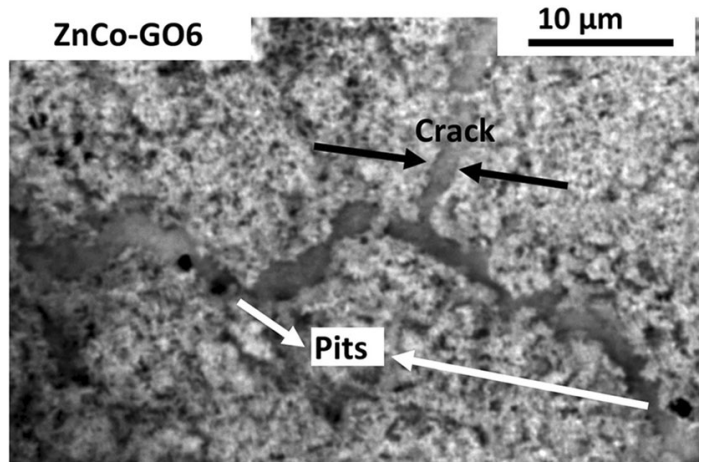

Fig. 18 - SEM image of the ZnCo-GO6 sample after $48 \mathrm{~h}$ exposure to 3.5 wt pet $\mathrm{NaCl}$ solution.
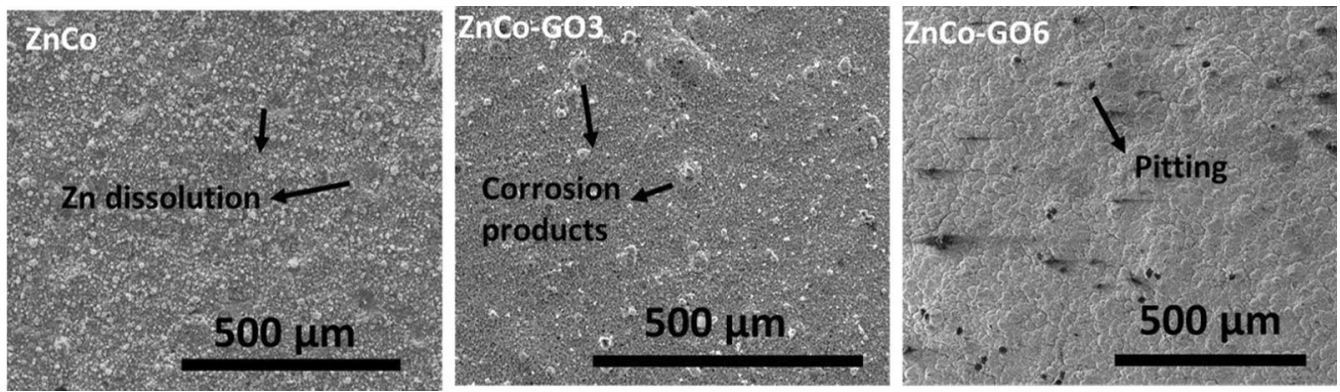

Fig. 17-SEM micrograph of $\mathrm{ZnCo}, \mathrm{ZnCo}-\mathrm{GO} 3$ and $\mathrm{ZnCo}-\mathrm{GO} 6$ after $48 \mathrm{~h}$ exposure to $3.5 \mathrm{wt}$ pet $\mathrm{NaCl}$ solution.

corrosion products in exposed $\mathrm{ZnCo}, \mathrm{ZnCo}-\mathrm{GO} 3$ and ZnCo-GO6 coatings, weight loss measurement was carried out. For this, a $1-\mathrm{cm}^{2}$ area of the coated samples was suspended in chloride media, and the change in weight was noted at intervals of $5,10,15,20,30,40,60$, 80 and 100 hours. Results obtained are shown in Figure 16. ZnCo-GO6 and $\mathrm{ZnCo}$ coating samples showed continuous weight loss due to continuous zinc dissolution owing to the absence of a stable oxide layer, while $\mathrm{ZnCo-GO3}$ showed relatively slower dissolution due to a relatively uniform oxide layer (formation of a stable ZHC layer making these coatings more corrosion resistant).

This is also apparent from the SEM image (Figure 17) of the $\mathrm{ZnCo}, \mathrm{ZnCo}-\mathrm{GO} 3$ and $\mathrm{ZnCo-GO6}$ samples after 48 hours of immersion in $\mathrm{NaCl}$. For the $\mathrm{ZnCo-GO6}$ 

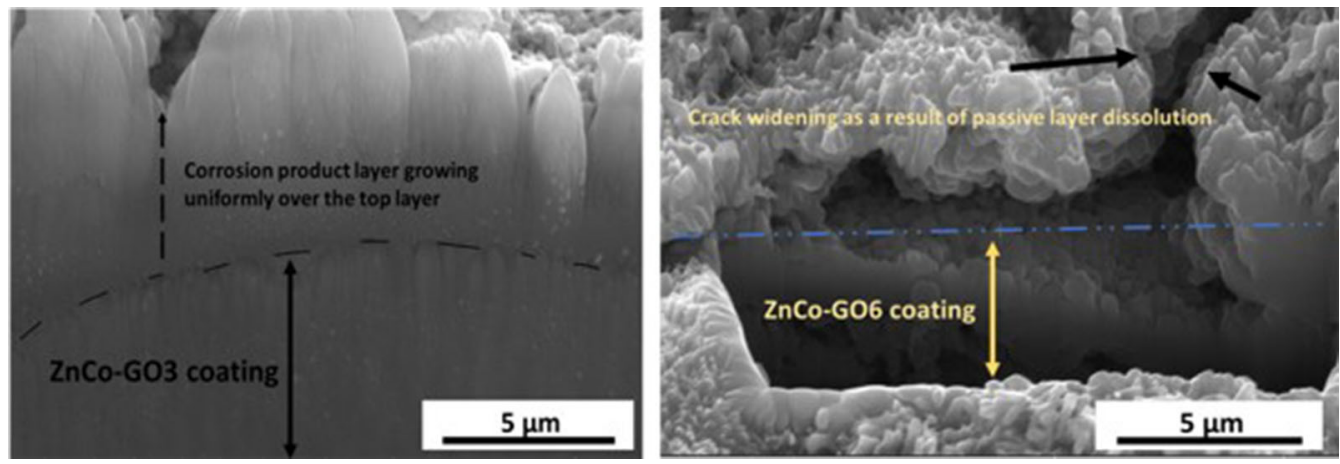

Fig. 19-FIB cross section of the $\mathrm{ZnCo-GO3}$ and $\mathrm{ZnCo}-\mathrm{GO} 6$ samples after $48 \mathrm{~h}$ exposure to $3.5 \mathrm{wt}$ pct $\mathrm{NaCl}$ solution.

sample, the adsorption of the halide ion over the passive film formed an electrostatic field across the electrolyte and film. These adsorbed ions then started to penetrate the film, which is easier at a point of defect in the film, leading to breakdown of the film and hence local dissolution of the surface. ${ }^{[37]}$ This phenomenon leads to pitting on the surface, evidence of which can be clearly observed in the SEM micrograph of the ZnCo-GO6 sample. Figure 18 shows the SEM image of the ZnCo-GO6 coating after corrosion marked with the location of pits and cracks. The origin of pits due to formation of galvanic couples at the grain boundaries is clearly visible. Figure 19 shows the cross-section of the corroded samples prepared using ion milling in SEM. A uniform oxide layer formation was observed in the case of $\mathrm{ZnCo-GO3,} \mathrm{while} \mathrm{for} \mathrm{the} \mathrm{ZnCo-GO6}$ sample, the passivating layer had cracks mostly originating from the mechanical stresses developed as a result of uneven morphology. These cracks, which widen with depth, allow fast migration of chloride ions/foreign ions, resulting in enhanced active dissolution of the material.

\section{CONCLUSIONS}

The corrosion behavior of ZnCo-graphene oxide composite coatings was studied. The corrosion rate decreased for the initial addition of graphene oxide to reach a minimum after which it increased with continued addition of graphene oxide. The initial reduction in the corrosion rate was attributed to the enhancement of the coating compactness, impermeability of graphene oxide and enhancement of the volume fraction of the intermetallic phase $\left(\mathrm{Zn}_{10.63} \mathrm{Co}_{2.34}\right)$. The enhancement of the corrosion rate after the optimum, which gave the lowest corrosion rate, was due to the increase in the morphologic roughness and surface defects because of non-uniform deposition of agglomerated graphene oxide.

\section{ACKNOWLEDGMENTS}

The authors acknowledge the research funding received from the SERB Government of India.

\section{REFERENCES}

1. D.A. Jones and B.E. Wilde: Corrosion, 1977, vol. 33, pp. 46-50.

2. D. Zhang, L. Li, Y. Wu, B. Zhu, and H. Song: Appl. Surf. Sci., 2019, vol. 473, pp. 493-99.

3. S. Thomas, N. Birbilis, M.S. Venkatraman, and I.S. Cole: Corros. Eng. Sci. Technol, 2012, vol. 68, p. 015009-1.

4. G.D. Wilcox and D.R. Gabe: Corros. Sci., 1993, vol. 35, pp. 1251-58.

5. D. Weng, P. Jokiel, A. Uebleis, and H. Boehni: Surf. Coat. Technol., 1997, vol. 88, pp. 147-56.

6. C.N. Panagopoulos, D.A. Lagaris, and P.C. Vatista: Mater. Chem. Phys., 2011, vol. 126, pp. 398-403.

7. J. Winiarski, W. Tylus, K. Winiarska, and B. Szczygieł: Corros. Sci., 2015, vol. 91, pp. 330-40.

8. N. Boshkov, K. Petrov, D. Kovacheva, S. Vitkova, and S. Nemska: Electrochim. Acta, 2005, vol. 51, pp. 77-84.

9. K. Higashi, H. Fukushima, T. Urakawa, T. Adaniya, and K. Matsudo: J. Electrochem. Soc., 1981, vol. 128, pp. 2081-85.

10. D. Koleva, N. Boshkov, G. Raichevski, and L. Veleva: Trans. IMF, 2005, vol. 83, pp. 188-93.

11. F. Rosalbino, G. Scavino, D. Macciò, and A. Saccone: Corros. Sci., 2014, vol. 89, pp. 286-94.

12. R. Ramanauskas, P. Quintana, L. Maldonado, P. Pomés, and M.A. Pech-Canul: Surf. Coat. Technol., 1997, vol. 92, pp. 16-21.

13. D. Lima-Neto, A.N. Correia, R.P. Colares, and W.S. Araujo: $J$. Braz. Chem. Soc., 2007, vol. 18, pp. 1164-75.

14. M.H. Gharahcheshmeh and M.H. Sohi: Mater. Chem. Phys., 2009, vol. 117, pp. 414-21.

15. M.H. Gharahcheshmeh and M.H. Sohi: Mater. Chem. Phys., 2012, vol. 134, pp. 1146-52.

16. T. Rabizadeh and S.R. Allahkaram: Mater. Des., 2011, vol. 32, pp. 133-38.

17. M. Abbasi, A. Abdollahzadeh, B. Bagheri, and H. Omidvar: $J$. Mater. Eng. Perform., 2015, vol. 24, pp. 5037-45.

18. J.H. Lee and S.K. Hwang: J. Nucl. Mater., 2003, vol. 321, pp. 238-48.

19. Y. Song, E.H. Han, D. Shan, C.D. Yim, and B.S. You: Corros. Sci., 2012, vol. 60 , pp. 238-45.

20. I.N. Sivagami, K. Prasanna, P. Santhoshkumar, Y.N. Jo, G.Y. Seo, and C.W. Lee: J. Alloys Compd., 2017, vol. 697, pp. $450-60$.

21. L.B. Tong, Q.X. Zhang, Z.H. Jiang, J.B. Zhang, J. Meng, L.R. Cheng, and H.J. Zhang: J. Mech. Behav. Biomed., 2016, vol. 62, pp. 57-70.

22. P.C. Tulio and I.A. Carlos: J. Appl. Electrochem., 2009, vol. 39, pp. $1305-11$

23. N. Boshkov, N. Tsvetkova, P. Petrov, D. Koleva, K. Petrov, G. Avdeev, C. Tsvetanov, G. Raichevsky, and R. Raicheff: Appl. Surf. Sci., 2008, vol. 254, pp. 5618-25.

24. B.P. Singh, B.K. Jena, S. Bhattacharjee, and L. Besra: Surf. Coat. Technol., 2013, vol. 232, pp. 475-81.

25. J.H. Huh, S.H. Kim, J.H. Chu, S.Y. Kim, J.H. Kim, and S.Y. Kwon: Nanoscale, 2014, vol. 6, pp. 4379-86.

26. M.K. Kumar, M.P. Singh, and C. Srivastava: RSC Adv., 2015, vol. 32 , pp. 25603-08. 
27. M.Y. Rekha and C. Srivastava: Corros. Sci., 2019, vol. 152, pp. $234-48$.

28. K.S. Jyotheender and C. Srivastava: Compos. B Eng., 2019, vol. 175 , p. 107145.

29. S. Arora, N. Kumari, and C. Srivastava: J. Alloys Compd., 2019, vol. 801 , pp. $449-59$

30. A. Gupta and C. Srivastava: Surf. Coat. Technol., 2019, vol. 375, pp. $573-88$.

31. S. Arora and C. Srivastava: Thin Solid Films, 2019, vol. 677, pp. $45-54$

32. Y. Zhu, S. Murali, W. Cai, X. Li, J.W. Suk, J.R. Potts, and R.S. Ruoff: Adv. Mater., 2010, vol. 22, pp. 3906-24.

33. L. Shahriary and A.A. Athawale: Int. J Renew. Energy Environ Eng., 2014, vol. 2, pp. 58-63.
34. M.E. Bahrololoom, D.R. Gabe, and G.D. Wilcox: J. Electrochem. Soc., 2013, vol. 150, pp. 144-51.

35. Y. Gao, X. Ren, J. Wu, T. Hayat, A. Alsaedi, C. Cheng, and C. Chen: Environ. Sci. Nano, 2018, vol. 5, pp. 362-71.

36. K.M. Behbahani, P. Najafisayar, and M. Pakshir: Corros. Eng. Sci. Technol., 2019, vol. 54, pp. 174-83.

37. S. Lichušina, A. Chodosovskaja, A. Sudavičius, R. Juškènas, D. Bučinskienèe, A. Selskis, and E. Juzeliūnas: Chemija, 2008, vol. 19, pp. 25-31.

Publisher's Note Springer Nature remains neutral with regard to jurisdictional claims in published maps and institutional affiliations. 